\title{
CAMA
}

Centre for Applied Macroeconomic Analysis

\section{Indeterminacy and Learning: An Analysis of Monetary Policy in the Great Inflation}

\section{CAMA Working Paper 16/2014 February 2014}

Thomas A. Lubik

Federal Reserve Bank of Richmond and

Centre for Applied Macroeconomic Analysis

\section{Christian Matthes}

Federal Reserve Bank of Richmond

\begin{abstract}
We argue in this paper that the Great Inflation of the 1970s can be understood as the result of equilibrium indeterminacy in which loose monetary policy engendered excess volatility in macroeconomic aggregates and prices. We show, however, that the Federal Reserve inadvertently pursued policies that were not anti-inflationary enough because it did not fully understand the economic environment it was operating in. Specifically, it had imperfect knowledge about the structure of the U.S. economy and it was subject to data misperceptions. The real-time data flow at that time did not capture the true state of the economy, as large subsequent revisions showed. It is the combination of learning about the economy and, more importantly, the use of data riddled with measurement error that resulted in policies, which the Federal Reserve believed to be optimal, but when implemented led to equilibrium indeterminacy in the economy.
\end{abstract}




\section{Keywords}

Federal Reserve, Great Moderation, Bayesian Estimation, Least Squares Learning

\section{JEL Classification}

C11, C32, E52

\section{Address for correspondence:}

(E) cama.admin@anu.edu.au

The Centre for Applied Macroeconomic Analysis in the Crawford School of Public Policy has been established to build strong links between professional macroeconomists. It provides a forum for quality macroeconomic research and discussion of policy issues between academia, government and the private sector.

The Crawford School of Public Policy is the Australian National University's public policy school, serving and influencing Australia, Asia and the Pacific through advanced policy research, graduate and executive education, and policy impact. 


\title{
Indeterminacy and Learning: An Analysis of Monetary Policy in the Great Inflation*
}

\author{
Thomas A. Lubik \\ Federal Reserve Bank of Richmond and $\mathrm{CAMA}^{\dagger}$ \\ Christian Matthes \\ Federal Reserve Bank of Richmond ${ }^{\ddagger}$
}

January 2014

\begin{abstract}
We argue in this paper that the Great Inflation of the 1970s can be understood as the result of equilibrium indeterminacy in which loose monetary policy engendered excess volatility in macroeconomic aggregates and prices. We show, however, that the Federal Reserve inadvertently pursued policies that were not anti-inflationary enough because it did not fully understand the economic environment it was operating in. Specifically, it had imperfect knowledge about the structure of the U.S. economy and it was subject to data misperceptions. The real-time data flow at that time did not capture the true state of the economy, as large subsequent revisions showed. It is the combination of learning about the economy and, more importantly, the use of data riddled with measurement error that resulted in policies, which the Federal Reserve believed to be optimal, but when implemented led to equilibrium indeterminacy in the economy.
\end{abstract}

\author{
JEL Classification: C11; C32; E52 \\ KEywords: $\quad$ Federal Reserve; Great Moderation \\ Bayesian Estimation; Least Squares Learning
}

\footnotetext{
*The views expressed in this paper are those of the authors and should not be interpreted as those of the Federal Reserve Bank of Richmond or the Federal Reserve System. We wish to thank our discussant Ryan Charour, Roberto Billi, Tim Cogley, Martin Ellison, Zheng Liu, Mark Watson, and seminar participants at UC Davis, the Federal Reserve Bank of San Francisco, Oxford University, Warwick University, the Bank of England, the 2013 meeting of the Society for Economic Dynamics in Seoul, and the 2013 Federal Reserve System Meeting in Macroeconomics for useful comments.

${ }^{\dagger}$ Research Department, P.O. Box 27622, Richmond, VA 23261. Tel.: +1-804-697-8246. Email: thomas.lubik@rich.frb.org.

${ }^{\ddagger}$ Research Department, P.O. Box 27622, Richmond, VA 23261. Tel.: +1-804-697-4490. Email: christian.matthes@rich.frb.org.
} 


\section{Introduction}

There are three strands of narratives about the Great Inflation and the Great Moderation in the academic literature. At opposite ends of the spectrum are the good/bad luck and good/bad policy stories. The 1970s were a time of economic upheaval with strong and persistent exogenous shocks that occurred with high frequency. It was simply bad luck to have been a central banker at that time since despite best intentions the incidence of shocks was too much for the central banker's arsenal to handle. When the 1980s came around, however, the reduced incidence and persistence of shocks rang in the Great Moderation. This view is exemplified by Sims and Zha (2006). An almost orthogonal narrative argues that the Federal Reserve conducted bad policy in the 1970s in that it was not aggressive enough in fighting inflation. It is only through Volcker's disinflation engineered through a highinterest rate policy that the Great Inflation was reined in. This bad policy view has been advocated by Clarida, Gali, and Gertler (2000) and subsequently Lubik and Schorfheide (2004). A third narrative, typically associated with Orphanides (2001), relies on the idea that the Federal Reserve did not perceive the economic scenario of the 1970s correctly. Data misperceptions led it to implement policies that delivered bad outcomes and that were only abated in the 1980s with a better understanding of the state of the world.

Our paper attempts to integrate the bad policy narrative with the data misperception narrative. More specifically, we provide an explanation for why the Federal Reserve, almost unwillingly, engaged at first in monetary policy that led to bad outcomes (the Great Inflation), but subsequently pursued a policy that resulted in good outcomes (the Great Moderation). We show that what appears in the data as good and bad outcomes is the result of an optimal policy problem under imperfect information. In doing so, we also integrate various recent contributions to the empirical and theoretical macroeconomic literature on learning.

We take as starting point the observation by Orphanides (2001) that the Federal Reserve did not perceive the productivity slowdown as it was occurring during the 1970s. We capture this misperception of the data by assuming that the Federal Reserve observes all data with error. In addition, we assume that the central bank does not know the true data-generating process. It gathers information by estimating a reduced-form VAR and then updates its beliefs about the state of the world and the underlying economic model using least-squares learning. The linear-quadratic optimal policy problem and its solution follows Primiceri (2006). 
Private sector behavior is captured by a typical New Keynesian framework that is close to that in Lubik and Schorfheide (2004) for reference purposes. The private sector knows the current monetary policy rule, forms rational expectations conditional on that rule, and assumes that the central bank's policy rule is time-invariant. The optimal rule derived from the central bank's policy problem thus combines with the private sector system into a rational expectations model. The original source of indeterminacy, that is, of multiplicity of solutions, that arise from the rational expectations system is the same as in Bullard and Mitra (2002), Woodford (2003), and Lubik and Schorfheide (2004); to wit, a violation of the Taylor principle. In the face of inflationary pressures, the central bank is not aggressive enough in raising the real rate of interest through its control of the nominal interest rate. As shown in these papers, the violation of the Taylor principle can be tied to the value of the policy coefficients in a (linear) interest rate rule.

In this paper, we thus provide a rationale for why the central bank may choose policy coefficients that inadvertently induce indeterminate outcomes. Given the learning mechanism and the misperception of the data due to measurement issues, the estimated coefficients of the central bank's reduced-form model, and thus the optimal policy coefficients, change period by period. The rational expectations equilibrium that arises each period is either unique or indeterminate given the policy rule in place. It is the endogenous shifts of the policy coefficients for fixed private sector parameters that move the economy across the threshold between the determinate and indeterminate regions of the parameter space. 'Bad policy', that is, indeterminacy, arises not because of intent but because of data mismeasurement and incomplete knowledge of the economy on the part of the central bank.

We estimate the model on real-time and final data using Bayesian methods. Our findings confirm the pattern of indeterminacy and determinacy during, respectively, the Great Inflation and the Great Moderation as identified by Lubik and Schorfheide (2004). Yet, this pattern is rationalized by data misperception, as was argued by Orphanides (2001), and by central bank learning, as was argued by Primiceri (2006). Federal Reserve policy led to indeterminate outcomes especially during the second half of the 1970s and before the disinflation under Volcker's chairmanship took hold. Afterwards, during the Volcker-Greenspan period, endogenous policy under learning with measurement error led to determinate outcomes in the Great Moderation.

The driver for these results is the extent of data revisions, and, thus, the ex post implied data misperception. We identify two especially prominent turning points when the initially observed output decline turned out to be much less dramatic following the revi- 
sion. In other words, the Federal Reserve was confronted with a situation where a decline in growth implied a lessening of inflationary pressures and a commensurately softer policy. Since the real economy was in better shape than originally believed, the Federal Reserve unwittingly violated the Taylor principle. Intriguingly, the largest change in policy, based on our estimated policy coefficients, occurred at the end of 1974, at the height of stagflation in the wake of the abandonment of price controls earlier that year. We find that the Federal Reserve under Burns pursued an aggressively anti-inflationary policy that resulted in a determinate equilibrium in the middle of the Great Inflation decade. This set in motion a shift toward an increasingly less accommodative policy stance that culminated in what has come to be known as the Volcker disinflation.

Traditionally, DSGE models for the analysis of monetary policy have been estimated using final data. It is only very recently that the importance of real-time data for understanding monetary policy decisions is being considered in this literature. ${ }^{1}$ Collard and Dellas (2010) demonstrate in an, albeit calibrated, ${ }^{2}$ New Keynesian DSGE model that monetary misperceptions, interpreted as the difference between real-time and revised data, are an important driver of observed economic fluctuations through a monetary policy transmission channel. They also show that this type of error imparts endogenous persistence on inflation dynamics without the need to introduce exogenous sources, such as price indexation. Neri and Ropele (2011) substantiate these insights by estimating a similar model for Euro area real-time data using Bayesian methods. They find that data misperceptions lead to estimated interest-rate smoothing coefficients that are higher than in the standard model. This finding parallels our results since an increasingly more inertial policy rule was one of the drivers of the switch from indeterminacy to determinacy in the early 1980s.

These papers model monetary policy in terms of an ad-hoc interest-rate feedback rule. This specification is by definition not designed to address the question that is central to the Lubik and Schorfheide (2004) interpretation of the Great Inflation, namely, why a central bank would, in fact, choose an apparently suboptimal policy that leads to indeterminacy. For this to happen, as we show in this paper, the central bank needs to face both model and data uncertainty. Pruitt (2012) develops a model along these lines by modifying Sargent,

\footnotetext{
${ }^{1}$ This is notwithstanding earlier contributions, such as Orphanides and Williams (2005), which use reduced-form models and nonsystem-based empirical methods to understand the implications of data misperceptions.

${ }^{2}$ Collard, Dellas, and Smets (2009) estimate this model using Bayesian methods and find strong support for the data mismeasurement specification in terms of overall fit. However, they do not use real-time data in their estimation. Consequently, measurement error takes on the role of a residual that is not disciplined by the relevant data concept in the empirical model.
} 
Williams, and Zha (2006) to take account of the real-time data issue that the Federal Reserve faced in the 1970s and 1980s. He shows that data misperceptions introduce sluggishness into the learning process which can jointly explain the persistent rise of inflation in the 1970s and the ensuing fall in the 1980s as the Federal Reserve gained a better understanding of the underlying true model. Pruitt's model is reduced form, in which the central bank chooses inflation and unemployment directly by minimizing quadratic loss in these two variables subject to a backward-looking and not micro-founded Phillips-curve relationship. He therefore cannot address the issue of indeterminacy during the Great Inflation. Moreover, he does not link his results to observed interest rate policies, that is, the Volcker disinflation in terms of a sharp Federal Funds rate hike is absent. ${ }^{3}$

Our paper also connects with the recent and emerging literature on regime-switching in macroeconomics. Following the contributions of Sims and Zha (2006), Davig and Leeper (2007), and Farmer, Waggoner, and Zha (2009), who study Markov-switching in the parameters of a structural VAR and in the coefficients of a monetary policy rule, Liu, Waggoner and Zha (2011), Bianchi (2013), and Davig and Doh (2013) estimate regimes and coefficients within the context of New Keynesian models. Generally, they find evidence of a regime shift in the early 1980s, thus supporting the argument in Lubik and Schorfheide (2004) who imposed this break date exogenously. What these papers do not allow for is the possibility of indeterminacy. High inflation is the outcome of a higher inflation target and a weaker policy response. Moreover, in this line of research the emphasis is on identifying the break endogenously within the confines of a DSGE model, whereas our paper proposes an explanation and a microfoundation for why these regime switches occurred.

The paper is structured as follows. The next section presents a simple example of the mechanism that we see at work. We first discuss determinate and indeterminate equilibria in a simple rational expectations model and then show how a least-squares learning mechanism can shift the coefficient that determines equilibrium outcomes across the boundary between determinacy and indeterminacy. We present our theoretical model in section 3 and discuss the timing and information assumptions in detail. We also explain how we compute equilibrium dynamics in our framework, and how we choose indeterminate equilibria. Section 4 elaborates on our choice of data and estimation issues. Section 5 presents the baseline estimation results, while section 6 contains a bevy of robustness checks. Section 7

\footnotetext{
${ }^{3}$ In a more recent contribution, Givens and Salemi (2013) estimate a simple forward-looking New Keynesian framework with real-time data and data misperception. The central bank solves optimal policy under discretion, but does not have to learn the structure of the economy. They only estimate the model from the early 1980s on and do not consider indeterminate equilibria.
} 
concludes and lays out a path for future research.

\section{A Primer on Indeterminacy and Learning}

Methodologically, the argument in our paper rests on two areas in dynamic macroeconomics, namely the determinacy properties of linear rational expectations models and the dynamic properties of least-squares learning. In this section, we introduce and discuss these issues by means of a simple example. The key points that we want to emphasize are: first, whether a rational expectations equilibrium is determinate or indeterminate depends on the values of structural parameters; second, in a learning environment the values of the inferred underlying structural parameters are varying over time. By connecting these two concepts we can develop a rationale for the behavior of the Federal Reserve during the Great Inflation of the 1970s and in later periods. The discussion of equilibrium determinacy borrows a simple framework from Lubik and Surico (2010), while the exposition of leastsquares learning is based on Evans and Honkapohja (2001).

\subsection{Determinate and Indeterminate Equilibria}

We consider a simple expectational difference equation:

$$
x_{t}=a E_{t} x_{t+1}+\varepsilon_{t},
$$

where $a$ is a structural parameter, $\varepsilon_{t}$ is a white noise process with mean zero and variance $\sigma^{2}$, and $E_{t}$ is the rational expectations operator conditional on information at time $t$. A solution to this equation is an expression that does not contain any contemporaneous endogenous variables and that depends only on exogenous shocks and lagged values of the variables in the information set. The type of solution depends on the value of the parameter $a$.

If $|a|<1$, there is a unique ('determinate') solution which is simply:

$$
x_{t}=\varepsilon_{t} .
$$

This solution can be found by iterating the equation (1) forward. Imposing covariance stationarity and utilizing transversality arguments results in this expression. Substituting the determinate solution into the original expectational difference equation verifies that it is, in fact, a solution.

On the other hand, if $|a|>1$, there are multiple solutions, and the rational expectations equilibrium is indeterminate. In order to derive the entire set of solutions we follow the approach developed by Lubik and Schorfheide (2003). We rewrite the model by introducing 
endogenous forecast errors $\eta_{t}=x_{t}-E_{t-1} x_{t}$, which by definition have the property that $E_{t-1} \eta_{t}=0$. This imposes restrictions on the set of admissible solutions. Define $\xi_{t}=E_{t} x_{t+1}$ so that equation (1) can be rewritten as:

$$
\xi_{t}=\frac{1}{a} \xi_{t-1}-\frac{1}{a} \varepsilon_{t}+\frac{1}{a} \eta_{t}
$$

We note that under the restriction $|a|>1$ this is a stable difference equation, where the process for $\xi_{t}$ is driven by the exogenous shock $\varepsilon_{t}$ and the endogenous error $\eta_{t}$. Any covariance-stationary stochastic process for $\eta_{t}$ is a solution for this model since there are no further restrictions on the evolution of $\eta_{t} \cdot{ }^{4}$

In general, the forecast error can be expressed as a linear combination of the model's fundamental disturbances and extraneous sources of uncertainty, typically labeled 'sunspots'. We can therefore write:

$$
\eta_{t}=m \varepsilon_{t}+\zeta_{t},
$$

where the sunspot $\zeta_{t}$ is a martingale-difference sequence, and $m$ is an unrestricted parameter. ${ }^{5}$ Substituting this into equation (3) yields the full solution under indeterminacy:

$$
x_{t}=\frac{1}{a} x_{t-1}+m \varepsilon_{t}-\frac{1}{a} \varepsilon_{t-1}+\zeta_{t} .
$$

The evolution of $x_{t}$ now depends on an additional (structural) parameter $m$ that indexes specific rational expectations equilibria.

Indeterminacy affects the behavior of the model in three main ways. First, indeterminate solutions exhibit a richer lag structure and more persistence than the determinate solution. This feature can be exploited for distinguishing between the two types of rational expectations equilibria for a given model. In the simple example, this is fairly obvious: Under determinacy the solution for $x_{t}$ is white noise, while under indeterminacy the solution is described by an $\operatorname{ARMA}(1,1)$ process. Specifically, the (composite) error term exhibits both serial correlation and a different variance when compared with the determinate solution. Second, under indeterminacy sunspot shocks can affect equilibrium dynamics. Other things being equal, data generated by sunspot equilibria are inherently more volatile than their determinate counterparts. The third implication is that indeterminacy affects the response of the model to fundamental shocks, whereas the response to sunspot shocks is uniquely

\footnotetext{
${ }^{4}$ In the case of determinacy, the restriction imposed is that $\xi_{t}=0, \forall t$, which implies $\eta_{t}=\varepsilon_{t}$.

${ }^{5}$ There is a technical subtlety in that $\zeta_{t}$ is, in the terminology of Lubik and Schorfheide (2003), a reducedform sunspot shock: $\zeta_{t}=m_{\zeta} \zeta_{t}^{*}$, with $m_{\zeta}$ a structural parameter and $\zeta_{t}^{*}$ a structural sunspot shock. Setting $m_{\zeta}=0$ would therefore result in a sunspot equilibrium without sunspots. Moreover, in less simple models, there would be additional restrictions on the coefficients since they depend in general on other structural parameters.
} 
determined. In the example, innovations to $\varepsilon_{t}$ could either increase or decrease $x_{t}$ depending on the sign of $m$.

What is important for the purposes of our paper is that the nature and properties of the equilibrium can change when the parameter $a$ changes in such a way that it moves across the boundary between determinacy and indeterminacy, which is given by $|a|=1$. The simple example assumes that the parameter $a$ is fixed. Our argument about indeterminacy, namely that it is caused by the central bank's data misperceptions, relies on the idea that parameters that affect the type of equilibrium, such as coefficients in a monetary policy rule, move around. We capture this rationale formally by means of a learning mechanism. The next section introduces this idea by discussing a simple example of how least-squares learning in combination with measurement error can result in time variation of the parameters that determine the type of equilibrium. ${ }^{6}$

\subsection{Indeterminacy through Learning}

We illustrate the basic mechanism by means of a simple example. The true data-generating process is equation (1), where we assume for illustration purposes that $a=0.01$. The solution under rational expectations is therefore $x_{t}=\varepsilon_{t}$, and thus determinate. In the environment with learning we assume that the agents have the perceived law of motion:

$$
x_{t}=b x_{t-1}+\nu_{t}
$$

which they estimate by least squares in order to gain knowledge about the underlying structural model. In our full model, this would be equivalent to the VAR that the central bank estimates to understand the evolution of the economy. In the determinate case $b=0$, while under indeterminacy $b=1 / a$. The least-squares estimate of the lag coefficient in the perecived law of motion, $\widehat{b}_{t}$, is varying over time as the information changes under constantgain learning. It is this mechanism that introduces persistence in the actual evolution of the economy. We note that in this special case any deviation from $\widehat{b}_{t}=0$ indicates an indeterminate equilibrium.

We can derive the actual law of motion, that is, the evolution of the data-generating process under the application of the perceived law of motion by substituting the latter into

\footnotetext{
${ }^{6}$ There is a subtlety here that we abstract from in this paper. We assume that the private sector operates under rational expectations in an environment where structural and policy parameters are believed to be fixed forever. The private sector is myopic in the sense that it does not realize that the policy parameters are time-varying and can change period by period. Moreover, the private sector does not take into account that the central bank solves a learning problem. These assumptions considerably simplify our computational work since, with respect to the latter assumption, we do no have to solve an additional private sector learning problem.
} 
(1). In our full model framework, the counterpart is the Federal Reserve's announcement of the policy rule to the private sector each period. Since $E_{t}\left(\widehat{b}_{t} x_{t}+\nu_{t+1}\right)=\widehat{b}_{t} x_{t}$ for given $\widehat{b}_{t}$, we find: ${ }^{7}$

$$
x_{t}=\left(1-a \widehat{b}_{t}\right)^{-1} \varepsilon_{t} .
$$

Although the rational expectations solution is i.i.d. the learning mechanism by itself introduces persistence into the actual path of $x_{t}$. An econometrician would therefore see persistent data and might erroneously conclude that they were generated from an indeterminate equilibrium, where $|a|>1$.

A central element of our argument is how mismeasured data influence beliefs and, thus, economic outcomes. ${ }^{8}$ We now demonstrate in a simple example how data mismeasurement can lead agents astray in that they believe to be in an indeterminate equilibrium. Empirical procedures that agents use in learning models, such as recursive-least squares algorithms, rely on forming second-moment matrices of observed data, which then enter the calculation of estimated coefficients. If the data are measured with error, even if that error has zero mean, this will lead to a biased estimate of this second-moment matrix and will therefore induce a bias in the parameter estimates. We present results from a simulation exercise along these lines in Figure 1. We draw i.i.d. shocks for 180 periods and estimate the lag coefficient in the perceived law of motion. Panel A of Figure 1 shows the estimate and the 5 th and 95th percentile bands for $\widehat{b}_{t}$ in the case when there is no measurement error. The estimates are centered at zero.

In a second simulation for the same draws of the shocks we add measurement error. From period 80 to 100 we force the learning agent to observe the actual data with error, which we assume to be equal to 2 standard deviations of the innovations in the model. After period 100, the measurement error disappears. As Panel B of Figure 1 shows, agents believe that there is substantial persistence in the economy as there would be under indeterminacy. The estimate of the perceived autoregressive reduced-form parameter $b$ reaches values as high as 0.4, which would indicate a structural parameter of $a=2.5$ and therefore an indeterminate solution to (1). Given the time series from Panel A, an econometrician tasked with deciding between a determinate and an indeterminate equilibrium would likely favor the latter because of the higher observed persistence. ${ }^{9}$

\footnotetext{
${ }^{7}$ We abstract from the subtlety that under indeterminacy the rational expectations solution is an $\operatorname{ARMA}(1,1)$ process, which could be reflected in the perceived law of motion.

${ }^{8}$ Pruitt (2012) elaborates in more detail why measurement error can have important consequences for models of learning.

${ }^{9}$ This intuition is discussed in more detail in Lubik and Schorfheide (2004). Figure 1 on p. 196 shows the likelihood functions for both cases.
} 
We want to emphasize that in our simulation the true value of $a=0.01$. The incorrect inference stems from the combination of least-squares learning and, more importantly, the introduction of measurement error. The simple example simulation thus shows that an economy can inadvertently drift into the indeterminacy region of the parameter space. We now turn to our full modelling framework, where we add an optimal policy problem to capture the idea that an optimizing central bank, despite best intentions, can inadvertently generate an indeterminate equilibrium in the economy.

\section{The Model}

\subsection{Overview and Timing Assumptions}

Our model consists of two agents, a central bank and a private sector. The central bank is learning about the state of the economy. It only has access to economic data that are measured with error and it is not aware of the mismeasurement. The central bank treats the observed data as if they are measured without error. ${ }^{10}$ Furthermore, the central bank does not know the structure of the data-generating process. Instead, it uses a reducedform specification to conduct inference. The central bank's policy is guided by an ad-hoc quadratic loss function, which is minimized every period to derive a linear optimal policy rule. The private sector knows the central bank's current period policy rule and determines inflation and output accordingly. It is aware of the mismeasurement problem that the central bank faces and the stochastic process that governs the measurement errors. The private sector itself does not face the mismeasurement problem; it observes the data perfectly. At the same time, the private sector is myopic in that it treats the policy coefficients, which are varying period by period, as fixed indefinitely. ${ }^{11}$

The timing of the model is such that the central bank estimates its model of the economy at the beginning of period $t$ using data up to and including period $t-1$. The central bank then minimizes its loss function subject to its estimated law of motion for the private sector, treating the parameter estimates as fixed. This results in optimal policy coefficients, which are then communicated to the public. The private sector observes the true state of the world and the policy coefficients. Then, shocks are realized and equilibrium outcomes are formed. The central bank's policy rule, taken as given by the private sector, and the structural equations of the private sector form a linear rational expectations model that can have a

\footnotetext{
${ }^{10}$ We consider alternative specifications (in which the central bank has access to final data) as a robustness exercise.

${ }^{11}$ We will discuss this "anticipated utility" assumption that the private sector shares with the central bank in more detail below.
} 
determinate or an indeterminate solution, depending in which region of the parameter space the estimates fall. The central bank observes these new outcomes and updates its estimates at the beginning of the next period.

\subsection{The Central Bank}

The central bank deviates from rational expectations in two critical aspects. First, it does not know the structure of the economy. Hence, it conducts inference based on a reducedform model. We follow the learning literature and endow the central bank with a VAR, which we restrict in such a way that it resembles the specification in Primiceri (2006), which serves as a benchmark. However, we explicitly focus on the nominal interest rate as the central bank's policy instrument. ${ }^{12}$ The central bank employs a learning mechanism, namely least-squares learning with constant gain, to update its model of the economy. The second key aspect of our approach is that the central bank observes the actual data with error. This is designed to mimic the problems central banks face when data arrive in real time but are potentially riddled with error.

We assume that the central bank observes $X_{t}$, a noisy measurement of the true state $X_{t}^{\text {true: }}$

$$
X_{t}^{\text {true }}=X_{t}+\nu_{t},
$$

where $\nu_{t}$ is a measurement error independent of the true outcome $X_{t}^{\text {true }}$. We assume that the error is serially correlated of order one:

$$
\nu_{t}=\rho_{\nu} \nu_{t-1}+\varepsilon_{t}^{\nu},
$$

where the Gaussian innovation $\varepsilon_{t}^{\nu}$ has zero mean and is independent of $X_{t}^{\text {true }}$. While it may be problematic to justify autocorrelated measurement errors on a priori grounds, we note that it is a key finding in Orphanides' (2001) analysis of monetary policy during the Great Inflation. Perhaps more importantly, we also assume that the central bank does not learn about the measurement error, which therefore persists during the estimation period. We consider alternative assumptions in a robustness exercise below.

The central bank sets the interest rate target:

$$
i_{t}^{C B}=i_{t}+\varepsilon_{t}^{i},
$$

based on a policy rule of the form:

$$
i_{t}^{C B}=\sum_{k=1}^{K} \alpha_{t}^{k} X_{t-k}+\gamma_{t} i_{t-1},
$$

\footnotetext{
${ }^{12}$ This is also a key difference to the approach in Pruitt (2012).
} 
where $\varepsilon_{t}^{i}$ is a zero-mean monetary policy implementation error. The policy coefficients $\alpha_{t}$ and $\gamma_{t}$ are chosen from an optimal policy problem. Time variation in the coefficients arises from the learning problem described below. We follow Primiceri (2006) and Sargent, Williams, and Zha (2006) in assuming that the central bank chooses the policy coefficients to minimize the quadratic loss function:

$$
\mathcal{W}_{t}=E_{t} \sum_{j=t}^{\infty} \beta^{(j-t)}\left[\left(\pi_{j}-\pi^{\text {target }}\right)^{2}+\lambda_{y}\left(\Delta y_{j}-\Delta y^{\text {target }}\right)^{2}+\lambda_{i}\left(i_{t}-i_{t-1}\right)^{2}\right],
$$

subject to estimated laws of motion for the relationship between the state variables, inflation $\pi_{t}$ and output growth $\Delta y_{t}$, the policy variable $i_{t}^{C B}$, and the definition of the policy instrument. $0<\beta<1$ is the constant discount factor, and $\lambda_{y}, \lambda_{i} \geq 0$ are weights in the loss function that we treat as structural parameters. ${ }^{13} \pi^{\text {target }}$ and $\Delta y^{\text {target }}$ are fixed target values for inflation and output growth, respectively.

In order to learn about the structure of the economy, the central bank estimates the following VAR:

$$
X_{j}=\sum_{k=1}^{n} A_{t, k} X_{j-k}+\sum_{l=0}^{m} B_{t, l} i_{j-l}+u_{j}
$$

The set of matrices $A$ and $B$ carry $t$-subscripts since they are re-estimated every period. They are, however, taken as fixed by the central bank when it minimizes its loss function. This leads to a standard linear-quadratic decision problem that the central bank needs to solve every period for a varying set of coefficient matrices. Similar to Primiceri (2006), we restrict the matrices in the central bank's model further so that we have one equation that resembles a backward-looking Phillips curve and another that resembles a dynamic IS-equation. Specifically, the central bank estimates the two-equation model:

$$
\begin{aligned}
\pi_{j} & =c_{\pi, t}+a_{t}(L) \pi_{j-1}+b_{t}(L) \Delta y_{j-1}+u_{t}^{\pi}, \\
\Delta y_{j} & =c_{y, t}+d_{t}(L) \Delta y_{j-1}+\delta_{t} i_{t-1}+u_{t}^{y} .
\end{aligned}
$$

We thus have $X_{t}^{\text {true }}=\left[\pi_{t}, \Delta y_{t}\right]^{\prime}$ as the nominal interest rate is not observed with error. All coefficients in the lag-polynomials $a_{t}(L), b_{t}(L)$, and $d_{t}(L)$, and the interest rate coefficient $\delta_{t}$ are potentially changing over time, as are the intercepts $c_{\pi, t}$ and $c_{y, t}$.

\footnotetext{
${ }^{13} \mathrm{~A}$ loss function of this kind can be derived from a representative household's utility function within a New Keynesian framework. In this case, $\lambda_{y}$ and $\lambda_{i}$ would be functions of underlying structural parameters. While it is conceptually possible to derive a loss function within our learning framework, it is beyond the scope of our paper. Nevertheless, using a welfare-based loss function with a reduced-form model of the economy might be problematic since it raises the question how the central bank can calculate the welfare-based loss function without knowledge of the structure of the economy.
} 
Given the estimates of the empirical model, the central bank needs to update its beliefs about the state of the economy. In line with much of the learning literature (see Evans and Honkapohja, 2001), we assume that it uses least-squares learning. The algorithm works as follows. Suppose the central bank wants to estimate an equation of the following form:

$$
q_{t}=p_{t-1}^{\prime} \phi_{t}+\xi_{t}
$$

where $q_{t}$ is the dependent variable or a vector of dependent variables, $p_{t-1}$ a vector or matrix of regressors, $\xi_{t}$ the residual(s), and $\phi_{t}$ the vector of parameters of interest. The least-squares learning algorithm can be written as:

$$
\begin{aligned}
R_{t} & =R_{t-1}+g_{t}\left(p_{t-1} p_{t-1}^{\prime}-R_{t-1}\right), \\
\phi_{t} & =\phi_{t-1}+g_{t} R_{t}^{-1} p_{t-1}\left(q_{t}-p_{t-1}^{\prime} \phi_{t-1}\right),
\end{aligned}
$$

which are the updating formulas for recursive least-squares estimation. $R_{t}$ is an estimate of the second-moment matrix of the data. A key parameter is the gain $g_{t}$. The standard assumption in the literature, as in Primiceri (2006) and Sargent, Williams, and Zha (2006), is to use a constant gain $g_{t}=g$. This amounts to assuming that the agents who estimate using constant gain think that parameters drift over time. The size of this gain determines by how much estimates are updated in light of new data. It encodes a view about how much signal (about the coefficients) and how much noise is contained in a data point. We initialize $R_{t}$ and $\phi_{t}$ using a training sample, which we assume to consist of 10 quarters of real-time data. ${ }^{14}$ The central bank in our model estimates its two-equation model equation by equation, which is a standard assumption in the literature.

\subsection{The Private Sector}

The behavior of the private sector is described by a New Keynesian Phillips curve that captures inflation dynamics using both forward- and backward-looking elements:

$$
\pi_{t}-\bar{\pi}_{t}=\beta\left[\alpha_{\pi} E_{t} \pi_{t+1}+\left(1-\alpha_{\pi}\right) \pi_{t-1}-\bar{\pi}_{t}\right]+\kappa y_{t}-z_{t} .
$$

$0 \leq \alpha_{\pi} \leq 1$ is the coefficient determining the degree of inflation indexation, while $\kappa>0$ is a coefficient determining the slope of the Phillips curve. $z_{t}$ is a serially correlated shock with law of motion $z_{t}=\rho_{z} z_{t-1}+\varepsilon_{t}^{z}$. Output dynamics is governed by an Euler-equation:

$$
y_{t}=-\sigma^{-1}\left(i_{t}-\bar{i}_{t}-E_{t}\left(\pi_{t+1}-\bar{\pi}_{t}\right)\right)+E_{t} y_{t+1}+g_{t},
$$

\footnotetext{
${ }^{14} \mathrm{An}$ alternative is to use a decreasing gain. For instance, a recursive version of OLS would set the gain equal to a decreasing function of $t$.
} 
where $\sigma>0$ is the coefficient of relative risk aversion. $g_{t}$ is a serially correlated shock with law of motion $g_{t}=\rho_{g} g_{t-1}+\varepsilon_{t}^{g}$. The innovations to both $\operatorname{AR}(1)$ processes are Gaussian. $y_{t}$ can be interpreted as output relative to a stochastic trend. Shocks to the latter are captured by the generic process $g_{t}$. We connect $y_{t}$ in the structural private sector equations to output growth $\Delta y_{t}$ in the central bank's VAR via the measurement equation in the model's state-space representation as in An and Schorfheide (2007).

The private sector equations share the same structure as in Lubik and Schorfheide (2004) for reference purposes. The equations can be derived from an underlying utility and profit maximization problem of, respectively, a household and a firm. Since these steps are well known we do not report these derivations explicitly. We deviate from the standard specification in that we include the time-varying inflation target $\bar{\pi}_{t}$ separately in these equations because the views the private sector holds about the steady-state level of inflation change as the central bank changes its policy rule. The private sector knows the steady-state real interest rate and can thus infer the implied steady-state level of inflation from the current period monetary policy rule.

The private sector equation system is closed by the monetary policy reaction function (10). This results in the three-equation model that forms the backbone for the standard DSGE model used in the analysis of monetary policy (Smets and Wouters, 2003). The policy rule is communicated to the private sector after the central bank has solved its optimal policy problem. The private sector thus knows the time $t$ policy rule when making its decision at time $t$. We assume that the private sector believes the policy rule will not change in the future. This is akin to the anticipated utility assumption that the central bank is making above and that is more generally often made in the learning literature. ${ }^{15}$ More specifically, the private sector realizes that the central bank makes a mistake in terms of basing the policy rule decision on mismeasured data. Yet, it is myopic in the sense that it does not assign any positive probability to changes in that policy rule when making decisions.

\subsection{Deriving the Equilibrium Dynamics}

Conditional on the central bank's reaction function, the private sector generates the final data. The central bank observes these with error and uses them as an input in the next period's optimal policy problem under learning. The behavior of the two agents, the central bank and the private sector as a data-generating process for the final data, is thus intricately

\footnotetext{
${ }^{15}$ Cogley and Sargent (2008) present an extensive discussion of the game-theoretic concept of 'anticipated utility' and how it relates to Bayesian decisionmaking in a macroeconomic context.
} 
linked in an essentially nonlinear manner. We now describe how to combine the two systems into a state-space format that can be used for likelihood-based inference.

In order to derive the equilibrium dynamics we define the vectors $Q_{t}$ and $Z_{t}$. $Q_{t}$ contains all variables that directly enter the private agents equilibrium conditions: $Q_{t}=$ $\left[X_{t}^{\text {true }}, i_{t}, z_{t}, g_{t}\right]^{\prime} . Z_{t}$ adds to that vector the variables that are needed for the central bank's reaction function: ${ }^{16} Z_{t}=\left[Q_{t}, \nu_{t}, \nu_{t-1}, \nu_{t-2}, X_{t-1}^{\text {true }}, X_{t-2}^{\text {true }}\right]^{\prime}$. The private sector's equilibrium conditions and the definition of GDP growth can be stacked to give the following set of forward-looking equations:

$$
A Q_{t}=B E_{t} Q_{t+1}+C Q_{t-1}+\varepsilon_{t}^{Q} .
$$

$\varepsilon_{t}^{Q}$ contains all exogenous innovations that appear in the private sector equations described above. It is worth noting that the private sector structural equations do not feature time variation. It is only the time-varying nature of the central bank's decision rules (and the private sector's knowledge of those time-varying decision rules) that will make the private sector decision rules vary over time and allow the resulting rational expectations equilibrium to possibly drift between determinate and indeterminate regions.

Equation (21) can not yet be solved: There is no equation determining the nominal interest rate. In other words, $A, B$ and $C$ do not have full row rank. We will therefore combine equation (21) with the central bank's decision rule and the definition of the mismeasured economic data $X_{t}$ :

$$
A_{t}^{Z} Z_{t}=B_{t}^{Z} E_{t} Z_{t+1}+C_{t}^{Z} Z_{t-1}+\varepsilon_{t}^{Z}
$$

We define $\mathbf{1}^{i}$ to be a selector vector that selects $i_{t}$ from $Q_{t}$. $A_{t}^{Z}$ is then given by:

$$
A_{t}^{Z}=\left(\begin{array}{cccccc}
A & 0 & 0 & 0 & 0 & 0 \\
0 & I & 0 & 0 & 0 & 0 \\
0 & 0 & I & 0 & 0 & 0 \\
0 & 0 & 0 & I & 0 & 0 \\
0 & 0 & 0 & 0 & I & 0 \\
0 & 0 & 0 & 0 & 0 & I \\
\mathbf{1}^{i} & 0 & \alpha_{t}^{1} & \alpha_{t}^{2} & -\alpha_{t}^{1} & -\alpha_{t}^{2}
\end{array}\right) .
$$

It is not immediately obvious that $A_{t}^{Z}$ is a square matrix. The 0 and $I$ arrays are always assumed to be of conformable size. $B_{t}^{Z}$ is a matrix of zeroes except for the upper left-hand

\footnotetext{
${ }^{16}$ To economize on notation, we derive the equilibrium dynamics for our benchmark case in which the central bank reacts to three lags of inflation and output growth.
} 
corner where $B$ resides. $C_{t}^{Z}$ is given by:

$$
C_{t}^{Z}=\left(\begin{array}{cccccc}
C & 0 & 0 & 0 & 0 & 0 \\
0 & \rho_{\eta} & 0 & 0 & 0 & 0 \\
0 & I & 0 & 0 & 0 & 0 \\
0 & 0 & I & 0 & 0 & 0 \\
I & 0 & 0 & 0 & 0 & 0 \\
0 & 0 & 0 & 0 & I & 0 \\
\gamma_{t} & 0 & 0 & -\alpha_{t}^{3} & 0 & \alpha_{t}^{3}
\end{array}\right)
$$

$\varepsilon_{t}^{Z}$ contains all the i.i.d. Gaussian innovations in the model. At each date $t$, we can use standard tools to solve equation (22). The reduced form of the model is then given by:

$$
Z_{t}=S_{t} Z_{t-1}+T_{t} \varepsilon_{t}^{z}
$$

In order to compute a model solution when the equation solver indicates nonexistence of equilibrium, we use a projection facility. That is, if a policy rule in a certain period implies nonexistence of a stationary equilibrium, the policy rule is discarded and last year's policy rule is carried out. ${ }^{17}$ If the policy rule implies an indeterminate equilibrium, we pick the equilibrium chosen by the rational expectations solver as in Sims (2002).

\section{Data and Estimation}

\subsection{Data}

In our model, there are two data concepts. The key assumption we make is that the central bank only has access to real-time data. That is, its decisions are based on data releases as they first become available. These are then subject to data revisions later on. We therefore use real-time data from the Federal Reserve Bank of Philadelphia for the estimation problem of the central bank. Our sample period starts in 1968:Q3 based on data availability. The last data point is 2012:Q2. We use the first 10 quarters of data for a pre-sample analysis to initialize the agents' prior. The effective sample period over which the model is estimated starts therefore in 1970:Q2. The data are collected quarterly.

A central assumption in our framework is that the private sector serves as data-generating process for the final data. Our estimation combines real-time and final observations on output growth and the inflation rate in addition to the nominal interest rate, which is observed without error (since it is the policy instrument of the central bank). We use as policy rate the Federal Funds rate, whereas output growth is measured as the growth rate of real GDP,

\footnotetext{
${ }^{17}$ This is based on the approach used by Cogley, Matthes, and Sbordone (2011).
} 
and inflation is the percentage change in the GDP deflator. Figure 2 depicts the real-time and the final data for the growth rate in real GDP and in the GDP deflator. The Appendix contains further details on the construction of the data series.

In our estimation exercise, we find it convenient to calibrate some parameters. Table 1 lists the calibrated parameters and their source. We set the inflation target $\pi^{\text {target }}$ in the central bank's loss function to an annual rate of $2 \%$. While the Federal Reserve did not have an official inflation target for much of the sample period, we take it to be commonly understood, and even mandated by the (revision to the) Federal Reserve Act of 1977, that it pursued stable prices, a proxy for which we consider an inflation rate of $2 \%$. The output growth target $\Delta y^{\text {target }}$ is set to a quarter-over-quarter rate of $0.75 \%$, which is roughly the sample average. We fix the discount factor at $\beta=0.99$.

The model estimation turned out to be sensitive to the specification of the backwardlooking New Keynesian Phillips curve and Euler equations. For instance, Sargent and Surico (2011) find almost purely backward-looking dynamics in their rational-expectations model. We therefore experimented with various specifications of the lag terms in these equations. The best-fitting specification was one with a backward-looking coefficient of 0.5 in the New Keynesian Phillips curve and no backward-looking dynamics for the output gap in the Euler-equation. We thus fix the respective coefficients at these values in our estimation.

We assume that the lag length in all central bank regressions is 3. Based on a preliminary investigation, we found that for shorter lag lengths most of the draws from the posterior distribution would have implied indeterminacy throughout the sample, which we did not find plausible. We therefore fix the gain for the regressions at 0.01 , which is at the lower end of the values used in the learning literature. When we estimated this parameter (while restricting it to be no smaller than 0.01) all estimates clustered around this value. As in Primiceri (2006) we therefore chose to calibrate it.

\subsection{Likelihood Function and Bayesian Inference}

We use the Kalman filter to calculate the likelihood function. Let $Y_{t}$ denote the observables. Our solution method for solving linear rational expectations models, the Gensys algorithm from Sims (2002) and adapted by Lubik and Schorfheide (2003) for the case of indeterminacy, delivers a law of motion for each time period for the vector of variables as a solution to the expectational difference equations given before. The state-space system to calculate 
the likelihood function is then given by:

$$
\begin{aligned}
Y_{t} & =R Z_{t}+\varepsilon_{t}^{y}, \\
Z_{t} & =S_{t} Z_{t-1}+T_{t} \varepsilon_{t}^{z},
\end{aligned}
$$

where $S_{t}$ is the time $t$ solution to the above equation system.

A key element of the learning algorithm is the specification of the initial beliefs held by the central bank. In order to pin down the agent's beliefs, we follow Primiceri (2006) and use real-time data from a training sample, together with a fixed gain parameter. The training sample only includes the information available to the central bank at the end of the period, not the final data releases. We prefer this approach since otherwise the number of parameters to estimate becomes very large.

In our benchmark specification, we also assume that the central bank never has access to updated data and never learns the true values of the variables. This assumption is made for convenience but also parsimony: It relieves us from having to model the process by which data gets updated over time. In order to avoid stochastic singularity, when we use the full set of real-time and final data we add a monetary policy shock to the model. The central bank's decision problem is unaffected by this because of certainty equivalence. Furthermore, we assume that the measurement errors in the central bank's observation of output growth and inflation are $\mathrm{AR}(1)$ processes, the parameters of which we estimate along with the model's other structural parameters. In any case, the private sector knows the structure of the measurement errors and understands the central bank's informational shortcomings.

We use a standard Metropolis-Hastings algorithm to take 300,000 draws from which we discard the first 50,000 as burn-in. The estimation problem is computationally reasonably straightforward, but time consuming since we have to solve a linear-quadratic dynamic programming problem and a linear rational expectations model every period for every draw. ${ }^{18}$

\section{Estimation Results}

\subsection{Parameter Estimates, Impulse Responses and Equilibrium Determi- nacy}

Figure 3 shows the marginal posterior distributions for each parameter that we estimate, while Table 2 reports their median estimates and the 5 th and 95th percentile. The dotted line in each graph in Figure 3 represents the prior distribution. The data appear quite

\footnotetext{
${ }^{18}$ We also estimated the model using the adaptive Metropolis-Hastings algorithm of Haario, Saksman, and Tamminen (2001) to safeguard against any pathologies. The results remain unchanged.
} 
informative as the posteriors are generally more concentrated and often shifted away from the priors. The estimation algorithm seems to capture the behavior around the posterior mode reasonably well, with parameters being tightly estimated. The "supply" and "demand" shocks, $z_{t}$ and $g_{t}$, respectively, show a high degree of persistence at $\widehat{\rho}_{z}=0.93$ and $\widehat{\rho}_{g}=0.73$. These numbers are very close to those found by Lubik and Schorfheide (2004) and other papers in the literature for this sample period. While the measurement error in the inflation rate is small, not very volatile, and especially not very persistent $\left(\widehat{\rho}_{\pi}=0.08\right)$, the picture is different for output growth. Its median $\operatorname{AR}(1)$ coefficient is estimated to be $\widehat{\rho}_{y^{g \text { row } t h}}=0.48$, which is considerable. This observation appears to confirm the notion that the Federal Reserve missed the productivity slowdown in the 1970s and thus misperceived the state of the business cycle in their real-time observations of output growth. Finally, the estimates of the weights in the central bank's loss function reveal a low weight on output growth and a considerably stronger emphasis on interest rate smoothing. The latter especially generates the observed persistence in interest rate data.

Figure 4 contains the key result in the paper. It shows our model-based evaluation of which type of equilibrium the U.S. economy was in over the estimated sample period. For this purpose, we define a determinacy indicator as follows. A value of ' 1 ' indicates a unique equilibrium, while a value of ' 0 ' means indeterminacy. The indicator is computed by drawing from the posterior distribution of the estimated model at each data point, whereby each draw results in either a determinate or an indeterminate equilibrium. We then average over all draws, so that the indicator can be interpreted as a probability similar to the concept of a transition probability in the regime-switching literature. As it turns out, our estimation results are very unequivocal as far as equilibrium determinacy is concerned since the indicator attains either 0 or 1 .

Two observations stand out from Figure 4. First, the U.S. economy has been in a unique equilibrium since the Volcker disinflation of 1982:Q3, which, according to conventional wisdom, implemented a tough anti-inflationary stance through sharp interest rate increases. In the literature, these are commonly interpreted as a shift to a policy rule with a much higher feedback coefficient on the inflation term (see Clarida, Galí, and Gertler, 2000). The second observation is that before the Volcker disinflation the economy alternated between a determinate and an indeterminate equilibrium. The longest indeterminate stretch was from 1977:Q1 until 1980:Q4 which covers the end of Burns' chairmanship of the Federal Reserve, Miller's short tenure, and the early Volcker period of a policy of nonborrowed reserve targeting. This was preceded by a short determinacy period starting at the end of 1974 . The 
U.S. economy was operating under an indeterminate equilibrium at the beginning of our effective sample period.

We report impulse response functions to a monetary policy shock (an innovation to the central bank's interest rate target in equation (10) ) in Figure $5 .{ }^{19}$ Since the optimal policy rule changes period by period, there is a set of impulse reponses for each data point. We focus on four time periods, the first quarters of 1975, 1979, 1990, and the last data point in 2012. We established that the U.S. economy was operating in a determinate equilibrium in 1975, 1990, and 2012. In these periods, a monetary policy shock raises the Federal Funds rate, lowers inflation, and lowers output growth, just as the intuition for the basic New Keynesian framework would suggest. ${ }^{20}$ The strength of the individual responses depends solely on the policy coefficients since the other structural parameters of the model are treated as fixed for the entire sample.

The pattern for 1979 is strikingly different, however. In response to a positive interest rate shock, inflation and output growth both increase with a prolonged adjustment pattern for the former variable. Moreover, the Federal Funds rate remains persistently high for several years, as opposed to its response in 1975. The key difference is that the equilibrium in 1979 is indeterminate. This finding is consistent with the observation in Lubik and Schorfheide (2003) that indeterminacy changes the way a model's variables respond to fundamental shocks. This can be seen in our simple example where in the indeterminate solution (5) the response of $x_{t}$ to $\varepsilon_{t}$ depends on the sign of the indeterminacy parameter $m$. Furthermore, a quick calculation shows that the Taylor principle, in terms of the response of the real interest rate (that is, the nominal rate less one-step ahead inflation), is violated in 1979 despite the strong and persistent Federal Funds rate response.

Our benchmark results show that the analysis provided by Clarida, Galí, and Gertler (2000) and Lubik and Schorfheide (2004) is essentially correct. The U.S. economy was in an indeterminate equilibrium for much of the 1970s, which it escaped from only in the early 1980s during a period that coincided with changes in the Federal Reserve's operating procedures under Volcker's chairmanship; hence the moniker the Volcker disinflation. The

\footnotetext{
${ }^{19}$ Impulses responses to the other shocks are available on request. They are consistent with the pattern displayed in this Figure. Supply shocks raise output growth and lower inflation, while demand shocks lead to increases in both. The interest rate has a stabilizing effect by increasing in accordance with the feedback mechanism embodied in equation (11). The exception is the pattern for 1979, the reason for which we discuss in this section.

${ }^{20}$ This statement obviously has to be qualified for 2012 since the U.S. economy was operating under a zero lower bound for the Federal Funds rate, which we do not impose in order to stay within a linear framework. In this specific case, the interest rate response can be seen as that of a shadow interest rate that would obtain in the absence of the lower bound.
} 
mechanism through which the indeterminate equilibria arose and switches between the types of equilibria occurred is consistent with Orphanides' (2001) view that the Federal Reserve misperceived the incoming data. We attempt to capture this idea by means of a central bank learning framework. We now dig deeper into our model's mechanism to understand the origins of the Great Inflation and Volcker's disinflation.

\subsection{The Volcker Disinflation of $\mathbf{1 9 7 4}$}

What drives the switches between determinate and indeterminate equilibria is the policy chosen by the central bank. Depending on the incoming data, the optimal policy coefficients can change every period. This feature of our framework is a marked difference from much of the literature, which describes policy via a time-invariant rule that is possibly subject to exogenous breaks or regime switches. Moreover, we treat the structural parameters of the private sector as invariant over the entire sample period. This allows us to focus on the changing nature of the policy coefficients as the source of changes in equilibrium.

We contrast the optimal Federal Funds rate from the model with the actual rate in Figure 6. We note that for much of the sample period optimal policy is tighter than the actual realized policy rate. This obviously explains the determinate outcomes after the Volcker disinflation of 1982, as the Federal Reserve wanted to implement a tighter policy than was eventually realized. At the same time, we also note that during the indeterminacy period during the second half of the 1970s the perceived optimal Federal Funds rate path was considerably above the realized path. This illustrates the main point of our paper. The chosen policy appears quite aggressively anti-inflationary, but, as we know from the results above, it resulted in an indeterminate equilibrium for much on the 1970s and, hence, in the Great Inflation. Figure 6 also shows a quite dramatic interest rate hike in late 1974, when the Federal Reserve intended to raise the Federal Funds rate to almost 30\%. As Figure 4 shows, this generated a switch from indeterminacy to determinacy that persisted for a year despite a sharp reversal almost immediately. For the period of the Great Moderation the optimal policy tracks the realized path quite closely, thus confirming the anti-inflationary credentials of the Volcker-Greenspan period. ${ }^{21}$

In Figure 7, we plot the measurement errors in inflation and output growth against the determinacy indicator. This gives insight into the underlying determinants of the optimal

\footnotetext{
${ }^{21}$ Overall, our model captures the realized data quite well, which is admittedly not a very high bar to cross. A more stringent test of our model is whether it produces reasonable forecasts. Carboni and Ellison (2009) demonstrate that Sargent, Williams, and Zha (2006) fails along this dimension. We report one measure along this dimension in Figure 10, where we show one-step-ahead inflation forecasts of the private sector and the central bank. Either series lines up reasonably well with alternative inflation expectation measures.
} 
policy choice. The measurement error is the difference between the real-time data and the final data. A positive measurement error thus means that the data are coming in stronger than they actually are. Consider the inflation picture in the third quarter of 1974. The Federal Reserve observes inflation that is two percentage points higher than in the final revision, which is, of course, not known to the policymakers. We note that the true data, i.e., the final data, are generated by the private sector equations. The seemingly high inflation thus prompts the Fed to jack up the policy rate, as shown in Figure 6. This is quickly reversed, however, as the next data points indicate a negative measurement error in inflation and a considerable one in output growth. Because of the persistence in the learning process and the sluggishness of the Federal Reserve's backward-looking model, determinacy switches tend to last for several periods.

Figure 7 also shows that the volatility and extent of the measurement errors seemingly declined after the early 1980s. Arguably, this could be an underlying reason why the Great Moderation period is, in fact, one of equilibrium determinacy. Moreover, as time goes by, the learning central bank develops a better understanding of the underlying structural model and the nature of the measurement error simply because of longer available data series. Nevertheless, data misperception issues can still arise, as evidenced by the spike in late 2008 in output growth and the increased volatility of the inflation error during the Great Recession.

Whether an equilibrium is determinate or indeterminate is determined by the private sector equations once the central bank has communicated the policy rule for this period. ${ }^{22}$ The switches should therefore be evident from changes in the chosen policy parameters. We can back out time series for the policy coefficients from the estimated model. Since the specified form of the policy rule contains more lags, namely three, than is usual for the simple New Keynesian framework upon which most of our intuition is built, we report the normalized sum of those coefficients, that is, the long-run coefficients, to gauge the effective stance of policy in Figure 8.

At the beginning of the sample, the inflation coefficients are essentially zero. With only mild support from positive output coefficients, the resulting equilibrium in the economy is indeterminate. The switch to a determinate equilibrium in 1974:Q3 is evident from the sharp rise in the long-run inflation coefficient. This is accompanied by a smaller, yet still substantial increase in the output coefficient. The switch back to an indeterminate

\footnotetext{
${ }^{22}$ This is where the assumption of anticipated utility bears most weight since we can solve the linear rational expectations model in the usual manner (Sims, 2002) and do not have to account for the potential future switches in policy in every period.
} 
equilibrium during the late Burns-Miller period seems a knife-edge case as both inflation and output coefficients come down, but to levels that might not be considered a priori inconsistent with a determinate equilibrium. The behavior of the coefficient on the lagged interest rate is interesting in this respect. It is well known (Woodford, 2003) that highly inertial policy rules support determinate equilibria even if the inflation coefficients are not large. The rule becomes less inertial as the early 1970s progress, reaching almost zero in 1976. It then climbs only gradually which is consistent with the indeterminate equilibrium occurring in the late 1970s.

After 1980 the policy coefficients gradually move upward. Almost all of this movement is driven by the normalizing factor, that is, the coefficient on the lagged nominal interest rate. Individual policy coefficients show virtually no variation after the 1980s. What is striking from the graphs is that the Volcker disinflation is essentially absent from the output and inflation coefficients. It appears only as the endpoint of the gradual rise in the lagged interest-rate coefficient in 1982. We can therefore interpret the Volcker disinflation not as an abrupt change in the Federal Reserve's responsiveness to inflation, but rather as the culmination of a policy move toward a super-inertial policy. ${ }^{23}$ A more pointed explanation is that the Volcker disinflation happened in 1974 under Burns' chairmanship. The sudden spike in inflation prompted the Federal Reserve to act tough by sharply increasing its feedback coefficients and gradually implementing a more inertial regime, which is evident from the continuous rise of the coefficient on lagged inflation. It reached its long-run value right in time for what the literature has identified as the onset of the Volcker disinflation. The groundwork was prepared, however, by Burns in 1974.

The analysis of Liu, Waggoner, and Zha (2011) offers an interesting contrast to our interpretation of the determinacy episode of 1974-75. They find a short-lived switch to a high-inflation target regime (with a level of the inflation target around $5 \%$ in annual terms, see their Figure 4 on p. 281) that coincides with our switch to a determinate equilibrium. The inflation target in their model is the steady-state or long-run level of inflation if no further regime changes were to occur. The central bank in our model always targets $2 \%$ annual inflation, but as its views change, so does its perceived long-run level of inflation. It only has one instrument to balance two goals, an inflation target and a GDP growth target. Consequently, the long-run level of inflation is not necessarily equal to its target. Figure 9 depicts the perceived long-run view of inflation held by the Federal Reserve in our framework. We see that the estimated long-run level of inflation is in the ballpark of the Liu,

\footnotetext{
${ }^{23}$ Coibion and Gorodnichenko (2011) offer a similar interpretation.
} 
Waggoner and Zha (2011) estimate just before the switch to determinacy. This is driven in both frameworks by the inflationary spike of the first oil-price shock. What follows afterward is interpreted differently. Our Federal Reserve tightens policy and switches to an aggressively anti-inflationary regime, while the Liu-Waggoner-Zha Federal Reserve accommodates the spike by switching to a high-inflation target. Within a year, however, the long-run perceived level of inflation in our model decreases, as does the inflation target in the model of Liu, Waggoner, and Zha (2011).

Finally, we can also contrast the Federal Reserve's and the private sector's one-period ahead inflation expectations. These are reported in Figure 10. The private sectors' expectations are the rational expectations from within the structural model given the policy rule, while the Fed's expectations are computed from its reduced-form model as a oneperiod ahead forecast. The latter are noticeably less volatile and smoother than the former, which reflects the different nature of the expectation formation. Moreover, the Federal Reserve's expectations were consistently higher than the private sector's expectations during the Great Inflation, whereas in the Great Moderation the respective expectations line up more closely and fluctuate around a $2 \%$ inflation target. This is therefore further evidence of data misperceptions as the underlying source for indeterminate outcomes. The Federal Reserve consistently expected higher inflation than actually materialized and chose policy accordingly.

Our results thus confirm those of Clarida, Galí, and Gertler (2000), Lubik and Schorfheide (2004), and others that have argued that the Great Moderation was kick-started by a shift to a more anti-inflationary policy under Volcker; whereas the Great Inflation was largely the outcome of weak policy. Much of this literature rests, however, on sub-sample estimation with exogenous break dates. Moreover, it also often lacks a rationale as to why a central bank would pursue ostensibly sub-optimal policies. Our approach is not subject to the former concern; and we provide an answer to the latter question. Our model is estimated over the whole sample period, while the shifts between determinacy occur endogenously as the central bank changes its behavior in the light of new data. The seemingly sub-optimal behavior is rationalized by the signal extraction problem the policymakers face. From their perspective policy is chosen optimally. Where our results deviate from the previous literature is that they show that the 1970s also exhibited determinate equilibria, especially for an extended period in the middle of the decade.

The middle of the 1970s, that is, the time period for which we identified switches between indeterminacy and determinacy, coincides with one of the most tumultuous periods in U.S. 
economic history. The sharp run-up in inflation throughout 1974 that is visible in the data (see Figure 2) is commensurate with the end of price controls on April 30, 1974. The devaluation of the U.S. Dollar and the first oil price shocks were also contributing factors to the inflationary picture. Moreover, the winter of 1974-75 marked the most acute period of stagflation in U.S. history. The Burns Federal Reserve rose to the occasion by hiking interest rates to combat inflation, which is acknowledged by the literature (see Hetzel, 2008, pp. 108). Incoming data on real GDP in 1974:Q4 and 1975:Q5 showed a much weaker picture of the economy than was ultimately revealed. Facing political pressures for further stimulus to combat the recession the Federal Reserve relented and relaxed its tightening stance in mid-1975 which we pick up in our framework as a switch back to indeterminacy. Yet, throughout the remainder of the 1970s monetary policy, as Hetzel (2008, pp. 113) argues, remained disonflationary and exhibited an increasing focus on money growth targets, which we plausibly pick up in terms of a continuous shift to a more inertial policy rule. While Burns' record as chairman of the Federal Reserve may not quite deserve the exalted status attributed to Volcker, we argue that his performance during the 1970s warrants a second look.

\section{Robustness}

It is well known that models with learning are quite sensitive to specification assumptions. We therefore conduct a broad range of robustness checks to study the validity of our interpretation of the Great Inflation in the benchmark model. We find that our results are broadly robust. We begin by assessing the sensitivity of the baseline results to changes in individual parameters based on the posterior median estimates. This gives us an idea how significant, in a statistical sense, our determinacy results are. The second exercise involves changing the central bank's forecasting model to make it closer to the underlying structural model of the private sector. Both exercises confirm the robustness of our benchmark findings. These are sensitive, however, to a modification of how we capture the central bank's initial beliefs at the beginning of the sample. We show how alternative, but arguably equally plausible assumptions, change the determinacy pattern considerably over the full sample period. Finally, we also consider alternative information sets of the central bank, specifically the length of time after which it gains access to the final data. 


\subsection{Sensitivity to Parameters}

Our results in terms of the determinacy indicators are fairly unequivocal in terms of which equilibrium is obtained at each data point over the sample period. Probabilities of a determinate equilibrium are either zero or one. As we pointed out above, the determinacy indicator is an average over the draws from the posterior distribution at each point, which appears highly concentrated in either the determinacy or the indeterminacy region of the parameter space. A traditional coverage region to describe the degree of uncertainty surrounding the determinacy indicator would therefore not be very informative.

To give a sense of the robustness of the indicator with respect to variations in the parameters, we perform the following exercise. We fix all parameters at their estimated posterior means. We then vary each parameter one by one for each data point and each imputed realization of the underlying shocks and measurement errors, and record whether the resulting equilibrium is determinate or indeterminate. As the results of, for instance, Bullard and Mitra (2002) indicate, the boundary between determinacy and indeterminacy typically depends on all parameters of the model. In the New Keynesian framework specifically, it depends on the Phillips curve parameter $\kappa$ and the indexation parameter $\alpha_{\pi}$. While this certainly is the case in our model as well, ${ }^{24}$ we find, however, that the determinacy indicator is not sensitive to almost all parameters in the model, the exception being the two weights in the central bank's loss function, $\lambda_{y}$ and $\lambda_{i} \cdot{ }^{25}$.

We report the simulation results for the two parameters in Figures 11 and 12, respectively. We vary each parameter over the range $[0,1]$. Each point in the underlying grid in these figures is a combination of a quarterly calendar date and a value of the parameter within this range. We depict indeterminate equilibria in blue and determinate equilibria in red. The posterior median of $\lambda_{y}$ is 0.065 . The horizontal cross-section at this value replicates Figure 4. Indeterminacy in the early 1970s was followed by a determinate period around 1975, after which another bout of indeterminacy toward the late 1970s was eradicated by the Volcker disinflation.

Figure 11 shows that a higher weight on output growth in the Federal Reserve's loss function would generally tilt the economy toward indeterminacy, other things being equal. The reason is that a higher weight on output reduces the relative weight on inflation so that

\footnotetext{
${ }^{24}$ New analytical results by Bhattarai, Lee, and Park (2013) in a New Keynesian model with a rich lag structure support this conjecture.

${ }^{25}$ This finding is reminiscent of the results in Dennis (2006), who estimates these weights using likelihoodbased methods in a similar model, albeit without learning and measurement error. He finds that the main determinant of fit and of the location of the likelihood function in the parameter space is the central bank's preference parameters.
} 
in the presence of inflation surprises, be they in the actual or in the real-time data that are subject to measurement error, the central bank responds with less vigor in the implied policy rule. A second observation is that the indeterminacy and determinacy regimes in the early to mid-1970s are largely independent of the central bank's preferences. Similarly, the pattern of determinate equilibria from the mid-1990s on appears unavoidable in the sense that even a relatively stronger preference for output growth would not have resulted in indeterminacy. The pattern for variations in the weight on interest rate smoothing $\lambda_{i}$ is similar. At the posterior median of 0.65 the determinacy indicator is not sensitive to large variations in this parameter.

\subsection{Model Structure}

Our results obviously depend on the specification of the model used by the private sector, that is, the structural model that we regard as the data-generating process for the final data, and on the empirical model used by the central bank to learn about the private sector's model. In our baseline specification we chose a restricted VAR for the central bank's forecasting model, whereby we follow the by now standard specification of Primiceri (2006). It is restricted in the sense that we included a one-period lagged nominal interest rate in the output equation, but not lagged values for the inflation rate. Moreover, lag lengths were chosen by the usual criteria and not with respect to the ARMA-structure implied by the structural model.

We therefore consider an alternative specification that removes some of these restrictions. Specifically, we include lag polynomials for the inflation rate and the nominal interest rate in the empirical output equation. ${ }^{26}$ This brings the empirical model closer to the reducedform structural model since output growth in the Euler-equation (20) depends on the real interest rate path, whereas the New Keynesian Phillips curve (19) only depends on output. The results from this specification (not reported, but available upon request) are generally the same as for our benchmark. The determinacy period during the mid-1970s lasts longer; a determinate equilibrium now obtains at the beginning of the effective sample period. This is driven by a comparatively large measurement error in inflation at the beginning of the sample, which prompted a sharp initial interest rate hike. As we have seen in the baseline specification, switching dates between determinacy and indeterminacy are associated with large measurement errors.

\footnotetext{
${ }^{26}$ We are grateful to Alejandro Justiniano for suggesting this specification to us.
} 


\subsection{The Role of Initial Beliefs}

A key determinant of the model's learning dynamics is the choice of initial beliefs held by the central bank. Since updating the parameter estimates in the face of new data can be quite slow, initial beliefs can induce persistence and therefore make switching less likely, everything else equal. There is no generally accepted way to choose initial beliefs. In our baseline specification we pursued what we believe to be the most plausible approach in that we use a training sample to estimate initial beliefs as part of the overall procedure. We set the initial mean beliefs before the start of the training sample to zero and initialize $R$ (the recursively estimated second moment matrix of the data) to be of the same order of magnitude as the second moment matrix in the training sample. As an alternative, we pursue a variant of the model where we estimate the scale of the initial second moment matrix by estimating a scale factor that multiplies both initial $R$ matrices. Results (not reported, but available on request) are unchanged from our benchmark.

When we substantially change the magnitude of $R$ by making the initial values an order of magnitude larger, we do get changes in the indeterminacy indicator, but the value at the posterior mode of that specification is 30 log points lower than in our benchmark. The determinacy indicator for this specification is depicted in Figure 13. Indeterminacy lasts throughout the 1970s and well into the middle of the 1980s. Initial beliefs are such that policy is too accommodative and the data pattern in the 1970s is not strong enough to lead to different central bank policies. Moreover, the learning mechanism is moving slowly so that initial beliefs need not be dispersed quickly. In this specification it takes a while for the Federal Reserve to catch up after the period that is commonly associated with the Volcker disinflation. For the rest of the Volcker-Greenspan period, determinate equilibria obtain.

\subsection{The Information Set of the Central Bank}

In our benchmark case, we do not allow the central bank to use final data. This is obviously an extreme assumption since data revisions occur frequently and the revised data generally get closer to the final data. In our analysis, we treat the data vintage of 2012:Q3 as final, which it may not necessarily be since the Bureau of Economic Analysis periodically revises its procedures. In any case, the actual Federal Reserve during the third quarter of 2012 was certainly aware of the final data as of this date as opposed to the central bank in our stylized environment. We therefore assess the robustness of our findings with respect to the central bank's information set, namely which data it observes and when it does so.

First, we ask what would happen if the central bank had access to real-time data with 
a one-period lag. The indeterminacy indicator behaves quite erratically in this case (not reported). Moreover, the model's posterior mode takes on a value that is 600 log points lower than for our benchmark case. This implies that the alternative timing assumption is rejected by the data in favor of the benchmark specification. Next, we allow the central bank to use final data throughout. Since this specification features a smaller set of observables (mis-measured data does not enter the model anymore), we can not directly compare posterior values. The implied indeterminacy indicator in Figure 14, however, is closer to our benchmark case than the previous robustness check. The second switch to indeterminacy happens later in 1992, but we still see the temporary switch in the middle of the 1970s. Naturally, this assumption on the immediate availability of final data is a priori less reasonable since it implies knowledge that the central bank could not have had.

This result shows the centrality of data misperceptions in understanding the transition from the Great Inflation to the Great Moderation. As argued by Beyer and Farmer (2007), models with indeterminate equilibria have the tendency to dominate the data since they offer a route for estimation algorithms to capture the observed persistence in the data. This is evident from Figure 14 as indeterminacy lasts into the 1990s, well beyond a break date that most researchers would consider plausible. Data misperception is therefore the critical element that unifies the different strands of interpretation of the Great Inflation and the subsequent Great Moderation.

\section{Conclusion}

We argue in this paper that the Great Inflation of the 1970s can be understood as the result of equilibrium indeterminacy in which loose monetary policy engendered excess volatility in macroeconomic aggregates and prices. We show, however, that the Federal Reserve inadvertently pursued policies that were not anti-inflationary enough because it did not fully understand the economic environment it was operating in. Specifically, it had imperfect knowledge about the structure of the U.S. economy and it was subject to data misperceptions since the real-time data flow did not capture the true state of the economy, as large subsequent revisions showed. It is the combination of learning about the economy and, more importantly, signal extraction to filter out measurement noise that resulted in policies that the Federal Reserve believed to be optimal, but when implemented led to an indeterminate equilibrium in the economy.

This paper combines the insights of Clarida, Galí, and Gertler (2000) and Lubik and Schorfheide (2004) about the susceptibility of New Keynesian modelling frameworks to sub- 
optimal interest rate rules with the observation of Orphanides (2001) that monetary policy operates in a real-time environment with an imperfect understanding of the same. It is only the passage of time that improves the central bank's understanding of the economy through learning. Additionally, a reduction in measurement error, that is, a closer alignment of the real-time data with their final revisions, reduces the possibility of implementing monetary policies that imply indeterminacy. Consequently, and in this light, the Volcker disinflation and the ensuing Great Moderation can be understood as just the result of better data and improved Federal Reserve expertise.

The key contributions of our paper are therefore twofold. First, we offer an interpretation of the Great Inflation and the Great Moderation that combines and reconciles the good policy/bad policy viewpoint with the data misperception argument. The weakness of the former is that it offers no explanation for why the Burns-Miller Federal Reserve behaved in a manner that ostensibly led to an indeterminate equilibrium. We provide this explanation by introducing measurement error through data misperceptions into the methodological framework of Lubik and Schorfheide (2004). Interestingly, our results should also offer comfort to the good luck/bad luck viewpoint as espoused by, for instance, Sims and Zha (2006) since we find that the switches between determinacy and indeterminacy are largely driven by the good or bad luck of obtaining real-time data that are close, or not close, to the final data. The second contribution, and one that follows from the previous one, is that of a cautionary tale for policymakers. The possibility of slipping into an indeterminate equilibrium is reduced with better knowledge about the structure of the economy and the quality of the data.

The main criticism to be leveled against our approach is that the private sector behaves in a myopic fashion despite forming expectations rationally. In order to implement our estimation algorithm, we rely on the anticipated utility assumption of Sargent, Williams, and Zha (2006). This means that the private sector in the model maintains the belief, despite all evidence to the contrary, that policy, which is changing period by period, will be fixed forever. A key extension of our paper would therefore include private sector learning of the central bank's learning problem. 


\section{References}

[1] An, Sungbae and Frank Schorfheide (2007): "Bayesian Analysis of DSGE Models". Econometric Reviews, 26(2-4), pp. 113-172.

[2] Beyer, Andreas, and Roger E. A. Farmer (2007): "Testing for Indeterminacy: An Application to U.S. Monetary Policy: Comment". American Economic Review, 97(1), pp. 524-529.

[3] Bhattarai, Saroj, Jae Won Lee, and Woong Yong Park (2013): "Price Indexation, Habit Formation, and the Generalized Taylor Principle". Manuscript.

[4] Bianchi, Francesco (2013): "Regime Switches, Agents' Beliefs, and Post-World War II U.S. Macroeconomic Dynamics". Review of Economic Studies, 80(2), pp. 463-490.

[5] Bullard, James, and Kaushik Mitra (2002): "Learning About Monetary Policy Rules". Journal of Monetary Economics, 49(6), pp. 1105-1129.

[6] Carboni, Giacomo, and Martin Ellison (2009): "The Great Inflation and the Greenbook". Journal of Monetary Economics, 56(6), pp. 831-841.

[7] Clarida, Richard, Jordi Gali, and Mark Gertler (2000): "Monetary Policy Rules and Macroeconomic Stability: Evidence and Some Theory". Quarterly Journal of Economics, 115, pp. 147-180.

[8] Cogley, Timothy, Christian Matthes, and Argia Sbordone (2011): "Optimal Disinflation under Learning". Federal Reserve Bank of New York Staff Reports 524.

[9] Cogley, Timothy, and Thomas J. Sargent (2008): "Anticipated Utility and Rational Expectations as Approximations of Bayesian Decision Making". International Economic Review, 49(1), pp. 185-221.

[10] Coibion, Olivier, and Yurij Gorodnichenko (2011): "Monetary Policy, Trend Inflation and the Great Moderation: An Alternative Interpretation". American Economic Review, 101, pp. 341-370.

[11] Collard, Fabrice, and Harris Dellas (2010): "Monetary Misperceptions, Output, and Inflation Dynamics". Journal of Money, Credit and Banking, 42(2-3), pp. 483-502.

[12] Collard, Fabrice, Harris Dellas, and Frank Smets (2009): "Imperfect Information and the Business Cycle". Journal of Monetary Economics, 56(Supplement), pp. S38-S56. 
[13] Davig, Troy, and Taeyoung Doh (2013): "Monetary Policy Regime Shifts and Inflation Persistence". Forthcoming, Review of Economics and Statistics.

[14] Davig, Troy, and Eric M. Leeper (2007): "Generalizing the Taylor Principle". American Economic Review, 97(3), pp. 607-635.

[15] Dennis, Richard A. (2006): "The Policy Preferences of the US Federal Reserve". Journal of Applied Econometrics, 21, pp. 55-77.

[16] Evans, George W. and Seppo Honkapohja (2001): Learning and Expectations in Macroeconomics. Princeton University Press. Princeton, NJ.

[17] Farmer, Roger E.A., Daniel F. Waggoner, and Tao Zha (2009): "Understanding Regime-Switching Rational Expectations Models". Journal of Economic Theory, 144, pp. 1849-1867.

[18] Givens, Gregory E., and Michael K. Salemi (2013): "Inferring Monetary Policy Objectives with a Partially Observed State". Manuscript.

[19] Haario, Heiki, Eero Saksman, and Johanna Tamminen (2001): "An Adaptive Metropolis Algorithm". Bernoulli, 7(2), pp. 223-242.

[20] Hetzel, Robert L. (2008): The Monetary Policy of the Federal Reserve: A History. Cambridge University Press. New York, NY.

[21] Liu, Zheng, Daniel Waggoner and Tao Zha (2011): "Sources of Macroeconomic Fluctuations: A Regime Switching DSGE Approach". Quantitative Economics, 2(2), pp. 251-301.

[22] Lubik, Thomas A. and Frank Schorfheide (2003): "Computing Sunspot Equilibria in Linear Rational Expectations Models". Journal of Economic Dynamics and Control, 28(2), pp. 273-285.

[23] Lubik, Thomas A. and Frank Schorfheide (2004): "Testing for Indeterminacy: An Application to US Monetary Policy". American Economic Review, 94(1), pp. 190-217.

[24] Lubik, Thomas A. and Paolo Surico (2010): "The Lucas Critique and the Stability of Empirical Models". Journal of Applied Econometrics, 25, pp. 177-194.

[25] Neri, Stefano, and Tiziano Ropele (2011): "Imperfect Information, Real-Time Data and Monetary Policy in the Euro Area". Economic Journal, 122, pp. 651-674. 
[26] Orphanides, Athanasios (2001): "Monetary Policy Rules Based on Real Time Data". American Economic Review, 91(4), pp. 964-985.

[27] Orphanides, Athanasios, and John C. Williams (2005): "The Decline of Activist Stabilization Policy: Natural Rate Misperceptions, Learning, and Expectations". Journal of Economic Dynamics and Control, 29, pp. 1927-1950.

[28] Primiceri, Giorgio (2006): "Why Inflation Rose and Fell: Policymakers' Beliefs and US Postwar Stabilization Policy". Quarterly Journal of Economics, 121, pp. 867-901.

[29] Pruitt, Seth (2012): "Uncertainty Over Models and Data: The Rise and Fall of American Inflation". Journal of Money, Credit and Banking, 44(2-3), pp. 341-365.

[30] Sargent, Thomas J., and Paolo Surico (2011): "Two Illustrations of the Quantity Theory of Money: Breakdowns and Revivals". American Economic Review, 101(1), pp. 109-128.

[31] Sargent, Thomas J., Noah Williams, and Tao Zha (2006): "Shocks and Government Beliefs: The Rise and Fall of American Inflation". American Economic Review, 96(4), pp. 1193-1224.

[32] Sims, Christopher A. (2002): "Solving Linear Rational Expectations Models". Computational Economics, 20, pp. 1-20.

[33] Sims, Christopher A., and Tao Zha (2006): "Were There Regime Switches in U.S. Monetary Policy?" American Economic Review, 96(1), pp. 54-81.

[34] Smets, Frank and Raf Wouters (2003): "An Estimated Dynamic Stochastic General Equilibrium Model of the Euro Area". Journal of the European Economic Association, 1(5), pp. 1123-1175.

[35] Woodford, Michael (2003): Interest and Prices: Foundations of a Theory of Monetary Policy. Princeton University Press. 


\section{Appendix: Data Construction}

All data we use is quarterly. The Federal Funds rate is the average rate in a quarter obtained from the Board of Governors. For quarterly inflation and quarterly output growth data, we use the real-time database at the Federal Reserve Bank of Philadelphia. The inflation data is constructed using a GDP deflator-based price index since this index gives us the longest available time series. The real-time output growth series is constructed using the real output series. Both the output and price level series are seasonally adjusted. As a proxy for final data, we use the data of the most recent vintage we had access to when estimating the model (data up to 2012:Q1 available in 2012:Q2). The data starts in 1968:Q3. 
Table 1: Calibration

\begin{tabular}{|c|c|c|c|}
\hline Parameter & & Value & Source \\
\hline Inflation Target & $\pi^{\text {target }}$ & $2.00 \%$ & Implied FOMC Target \\
\hline Output Target & $\Delta y^{\text {target }}$ & $0.75 \%$ & Q/Q Sample Average \\
\hline Discount Factor & $\beta$ & 0.99 & Standard \\
\hline Indexation NKPC & $\alpha_{\pi}$ & 0.50 & Pre-Sample Estimate \\
\hline Habit Parameter & $\delta_{y}$ & 0.00 & Pre-Sample Estimate \\
\hline Lag Length in CB regression & $n$ & 3 & \\
\hline Gain Parameter & $g$ & 0.01 & \\
\hline
\end{tabular}

Table 2: Posterior Mean Estimates

\begin{tabular}{llccc}
\hline \hline & & & & \\
& & 5 th Percentile & Median & 95 th Percentile \\
\cline { 3 - 4 } Shocks: & $\rho_{z}$ & 0.91 & 0.93 & 0.94 \\
& $\rho_{g}$ & 0.70 & 0.73 & 0.76 \\
& $\sigma_{z}$ & 0.002 & 0.002 & 0.003 \\
& $\sigma_{g}$ & 0.011 & 0.012 & 0.014 \\
& $\sigma_{i}$ & 0.006 & 0.007 & 0.008 \\
Measurement: & $\rho_{\pi}$ & 0.03 & 0.08 & 0.17 \\
& $\rho_{y^{\text {growth }}}$ & 0.41 & 0.48 & 0.56 \\
& $\sigma_{\pi}$ & 0.0020 & 0.0022 & 0.0024 \\
Structural: & $\sigma_{y^{\text {growth }}}$ & 0.0054 & 0.0059 & 0.0064 \\
\cline { 3 - 4 } & $\kappa$ & & & \\
& $\kappa$ & 0.03 & 0.04 & 0.05 \\
& $\lambda_{y}$ & 0.06 & 0.07 & 0.08 \\
& $\lambda_{i}$ & 0.54 & 0.65 & 0.76 \\
\hline \hline
\end{tabular}



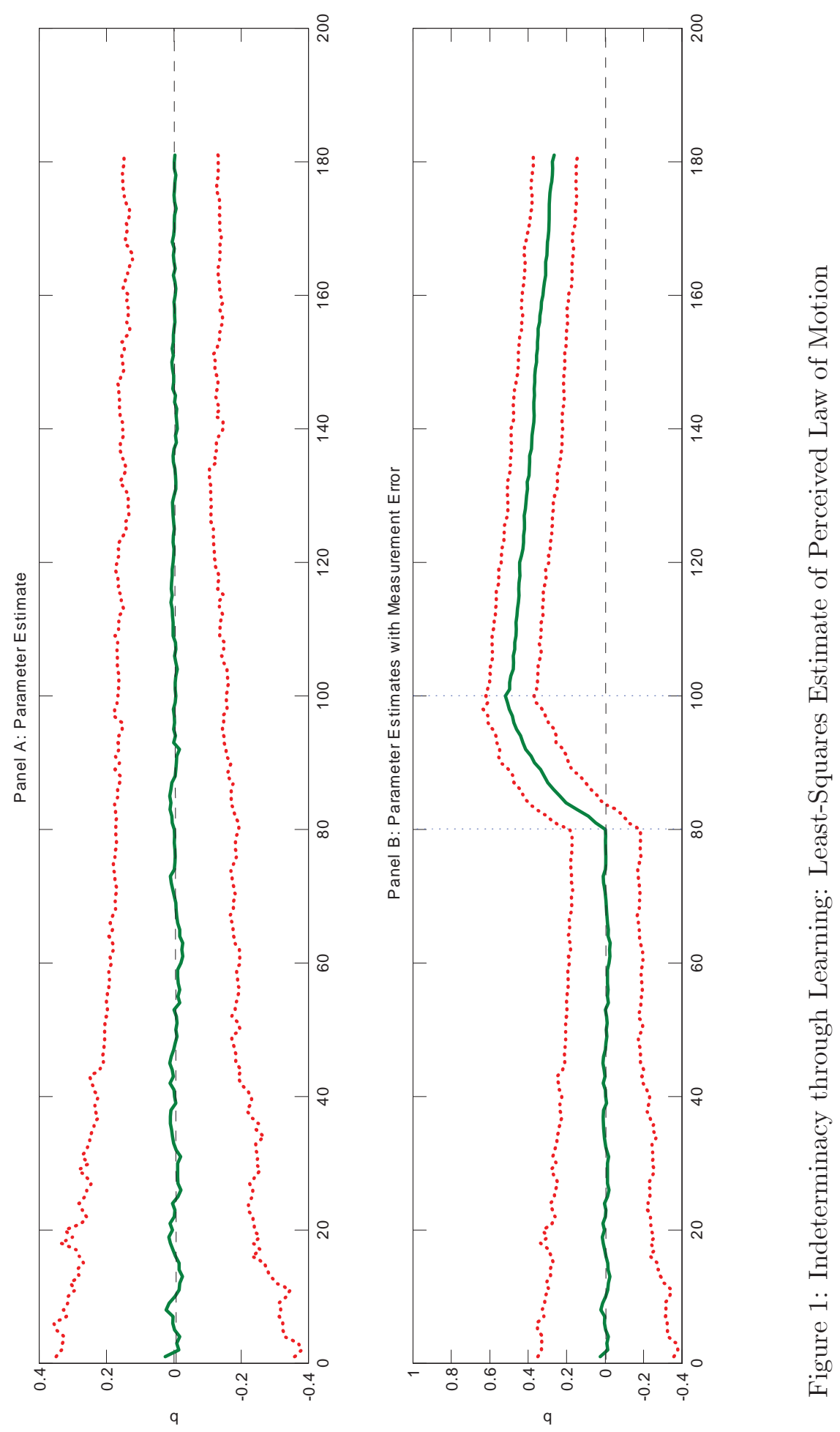

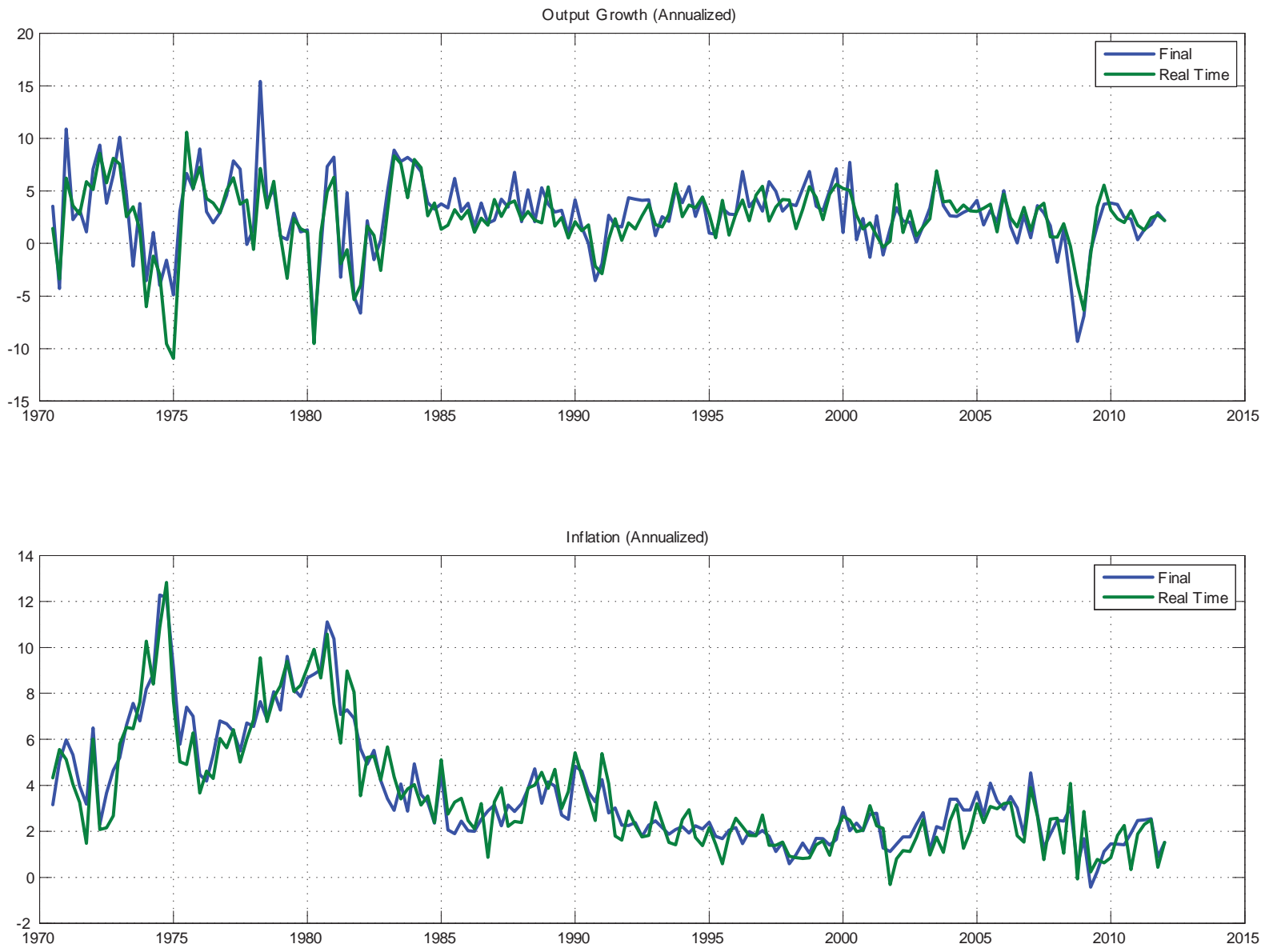

Figure 2: Real-Time and Final Data: Real GDP Growth and GDP Deflator 

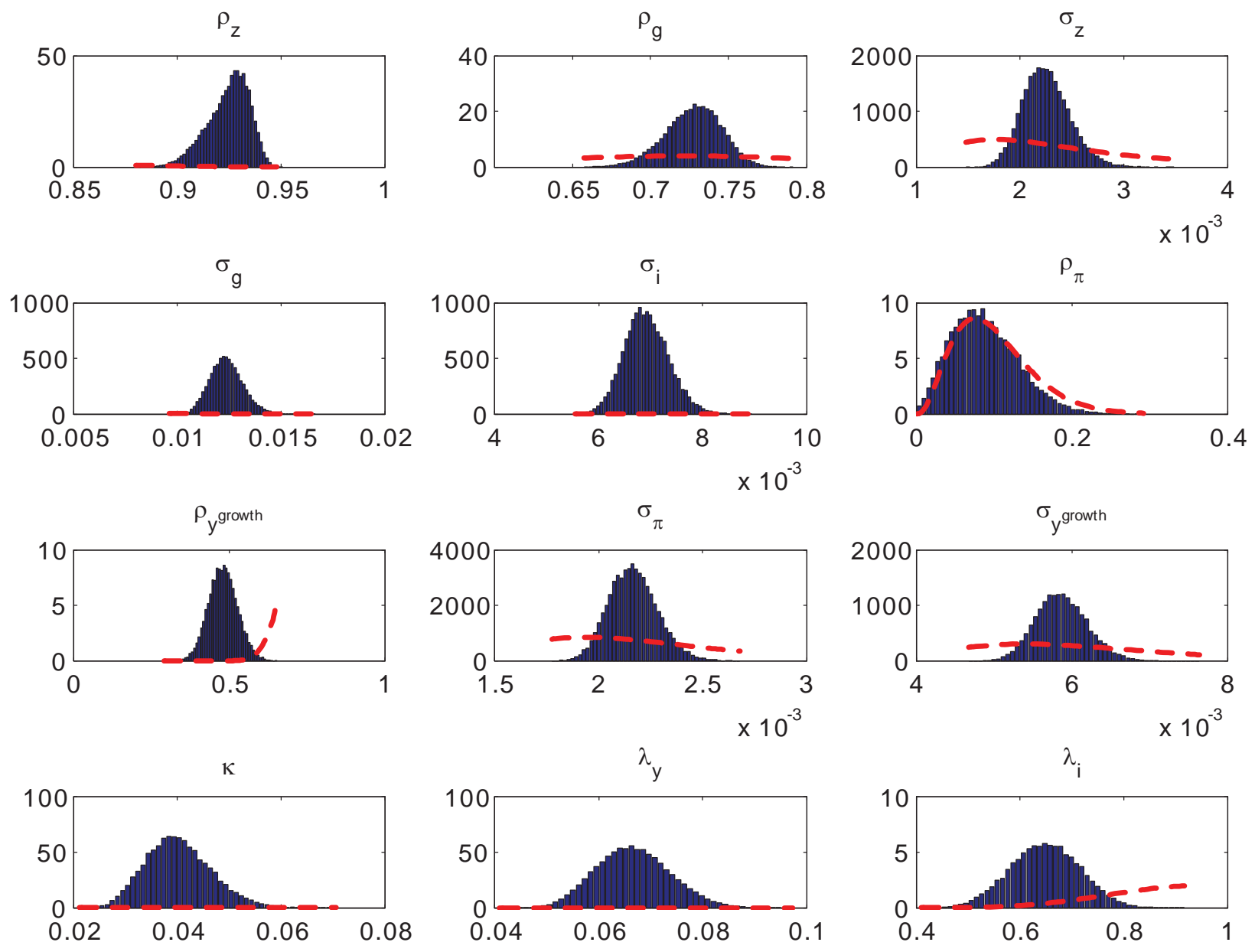

Figure 3: Prior and Posterior Parameter Density (Benchmark Specification) 


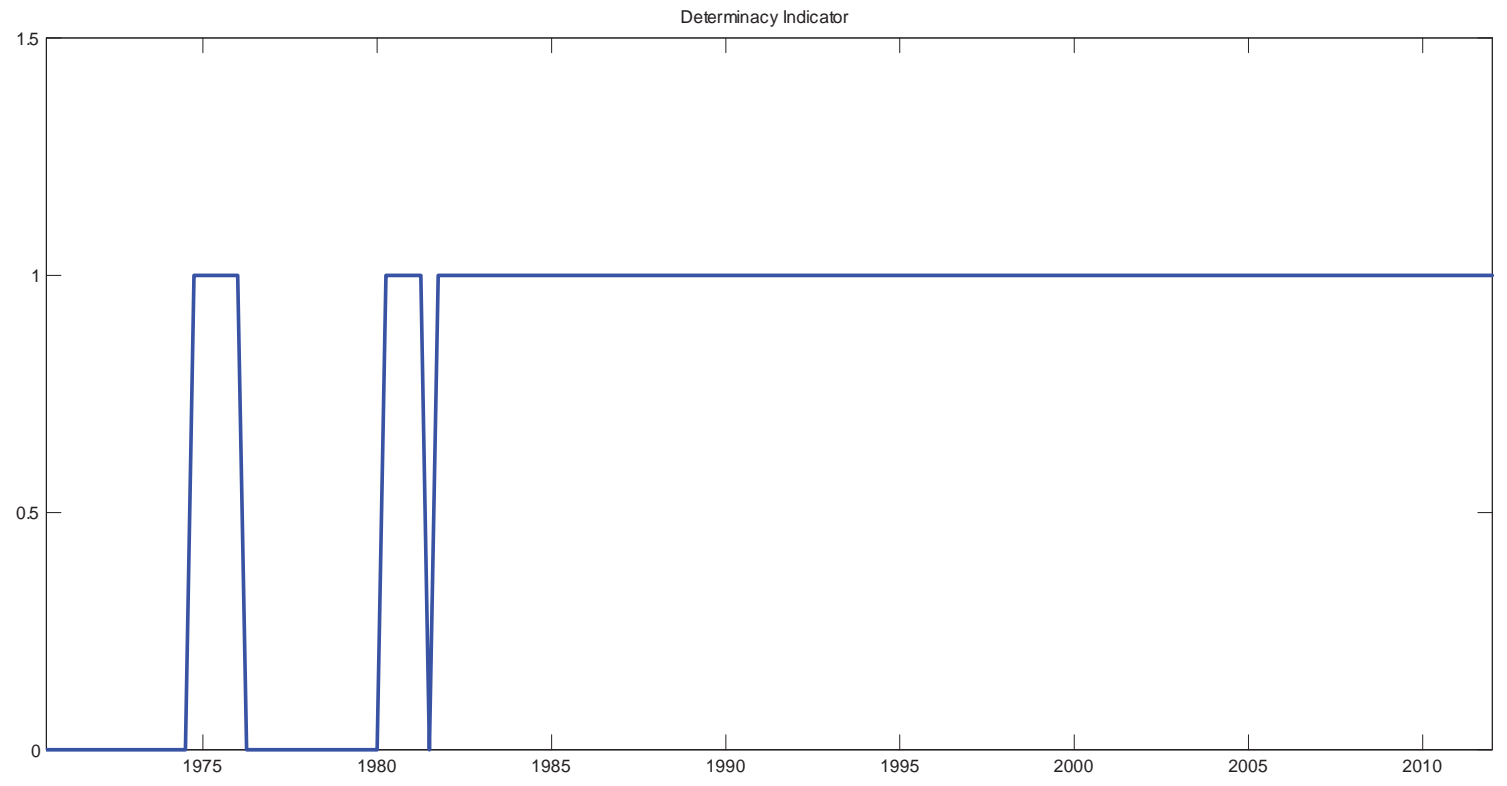

Figure 4: Determinacy Indicator: Benchmark Specification 

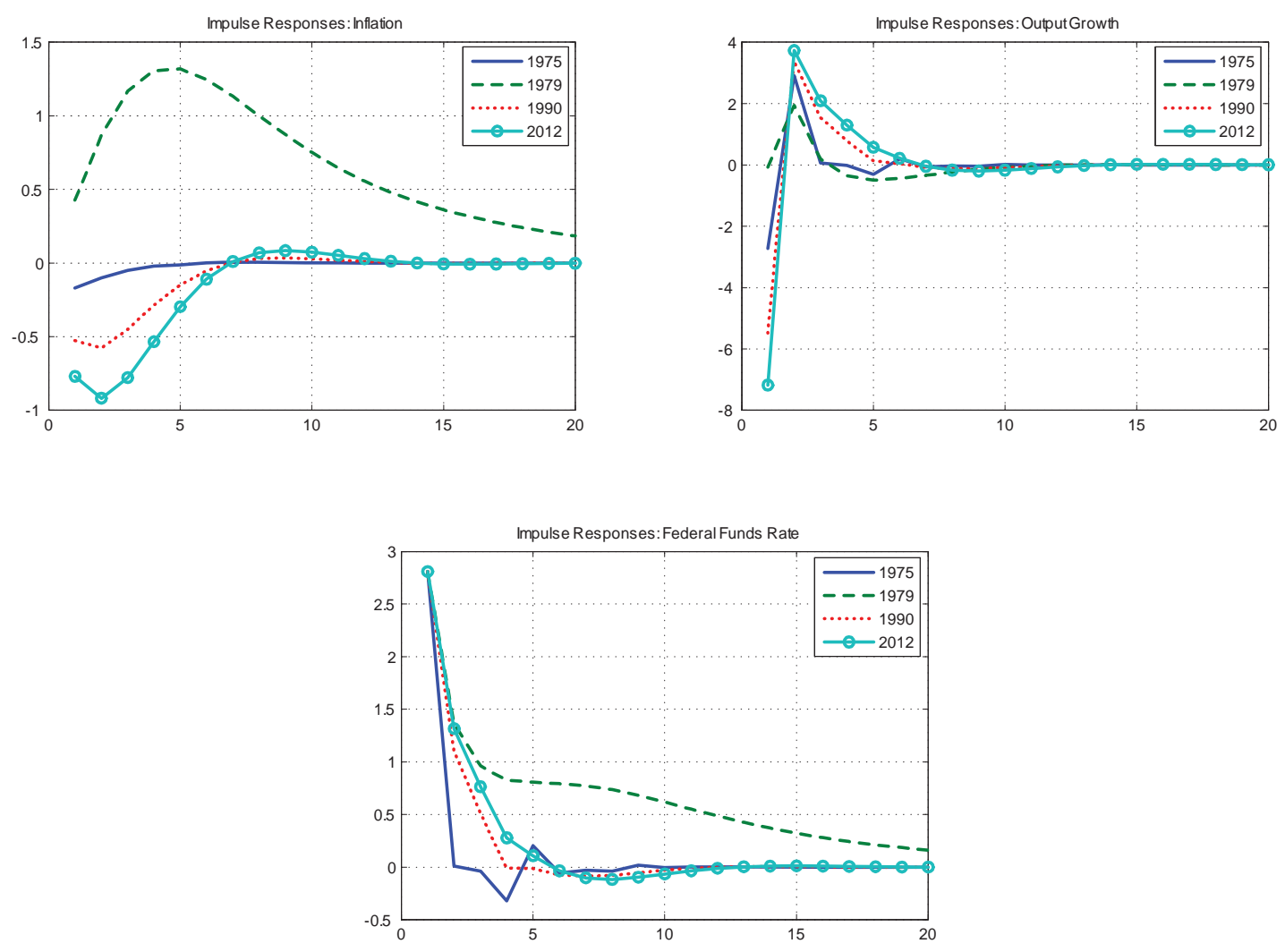

Figure 5: Impulse Response Functions to a Monetary Policy Shock 


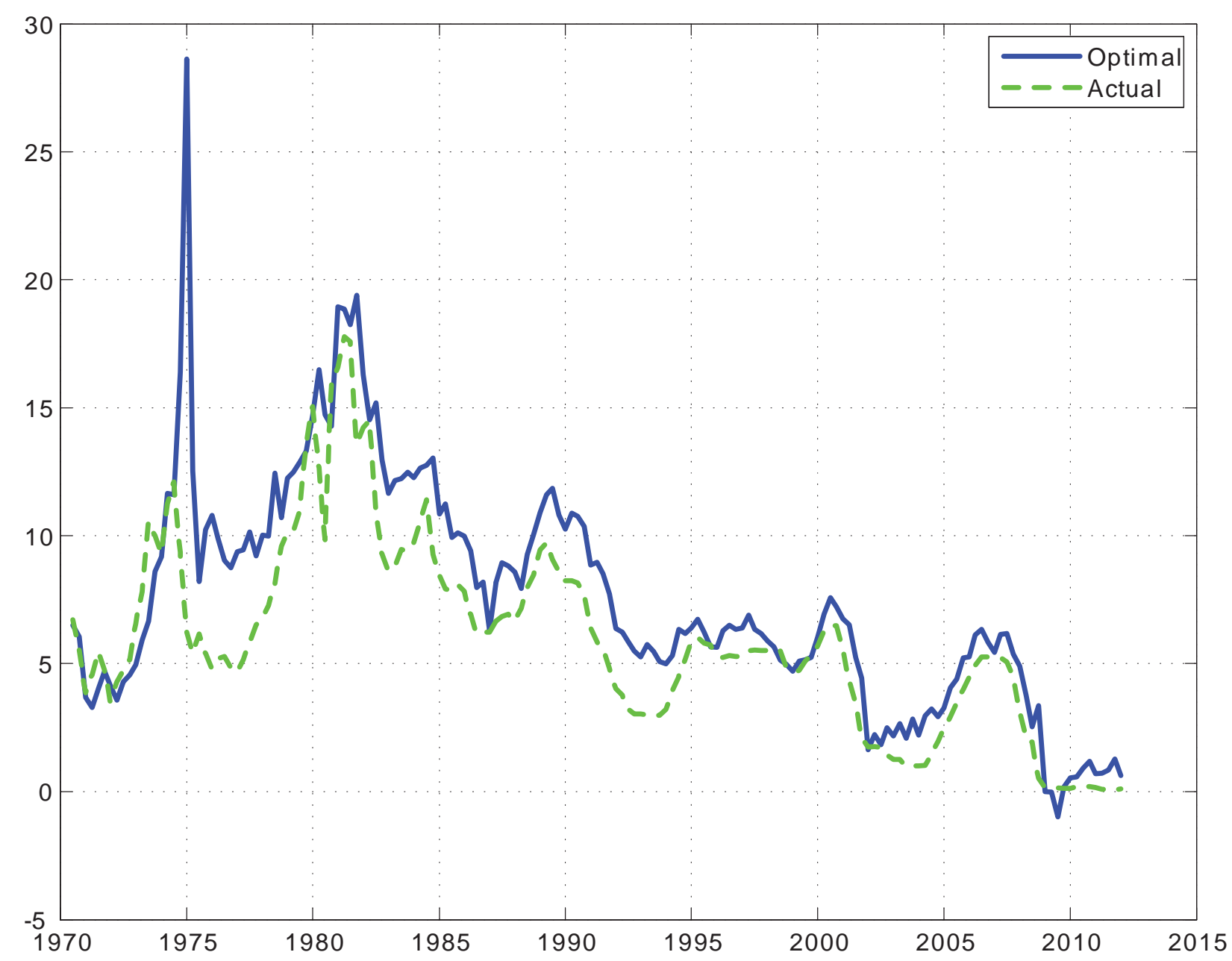

Figure 6: Evolution of the Federal Funds Rate: Actual vs. Prescribed under Optimal Policy 

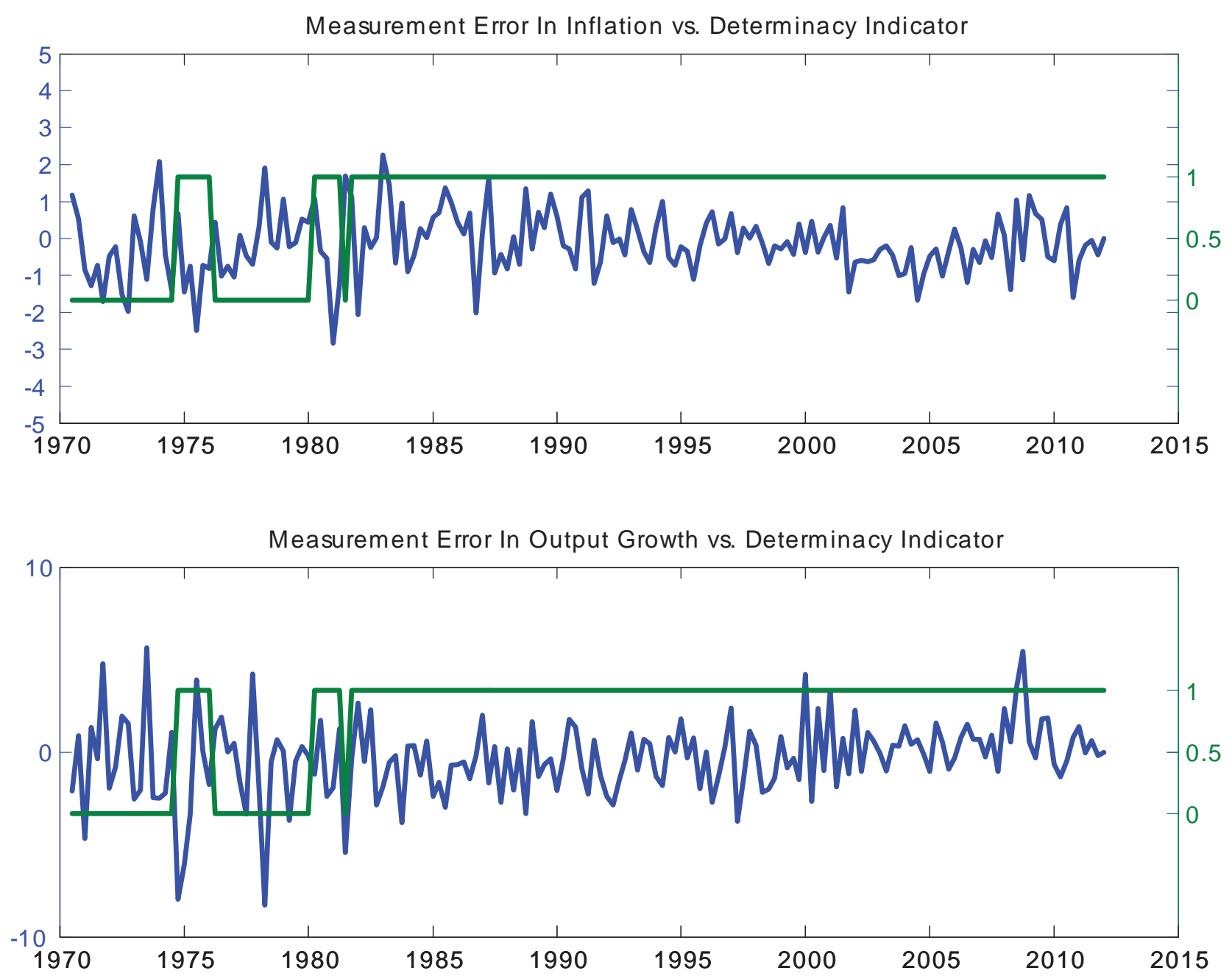

Figure 7: Estimated Measurement Errors 

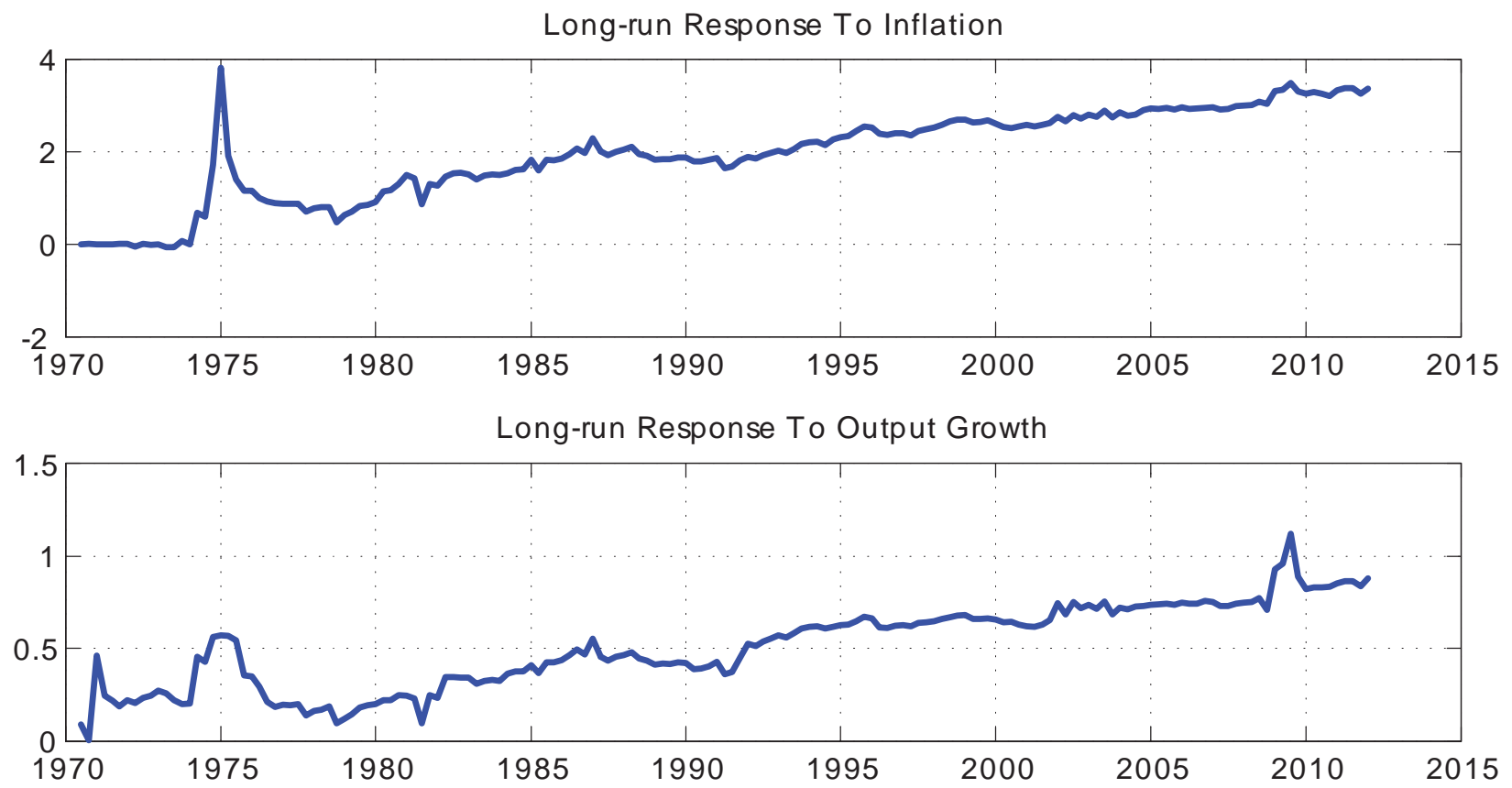

Response To The Lagged Nominal Interest Rate

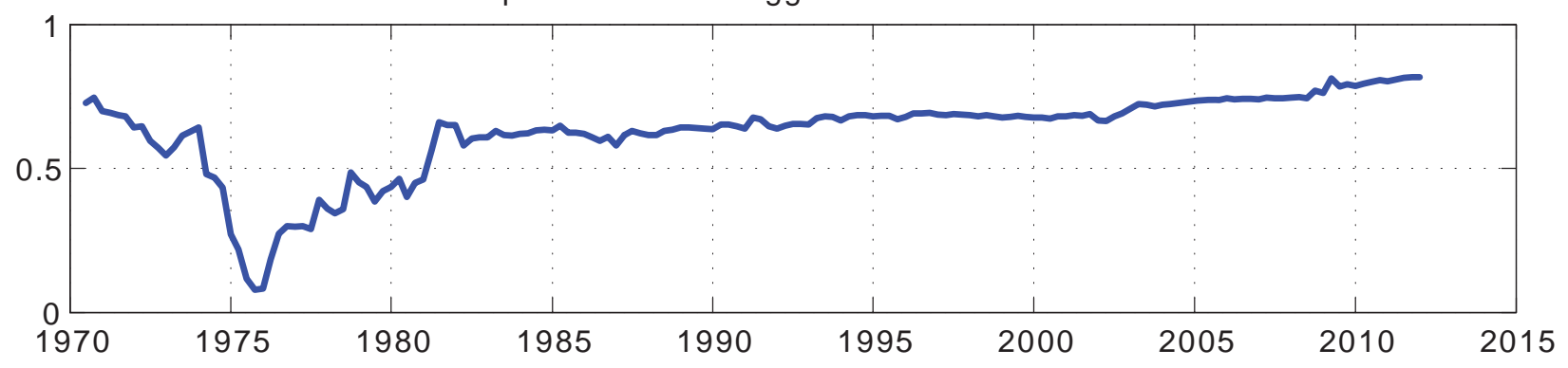

Figure 8: Long-Run Policy Coefficients: Benchmark Specification 


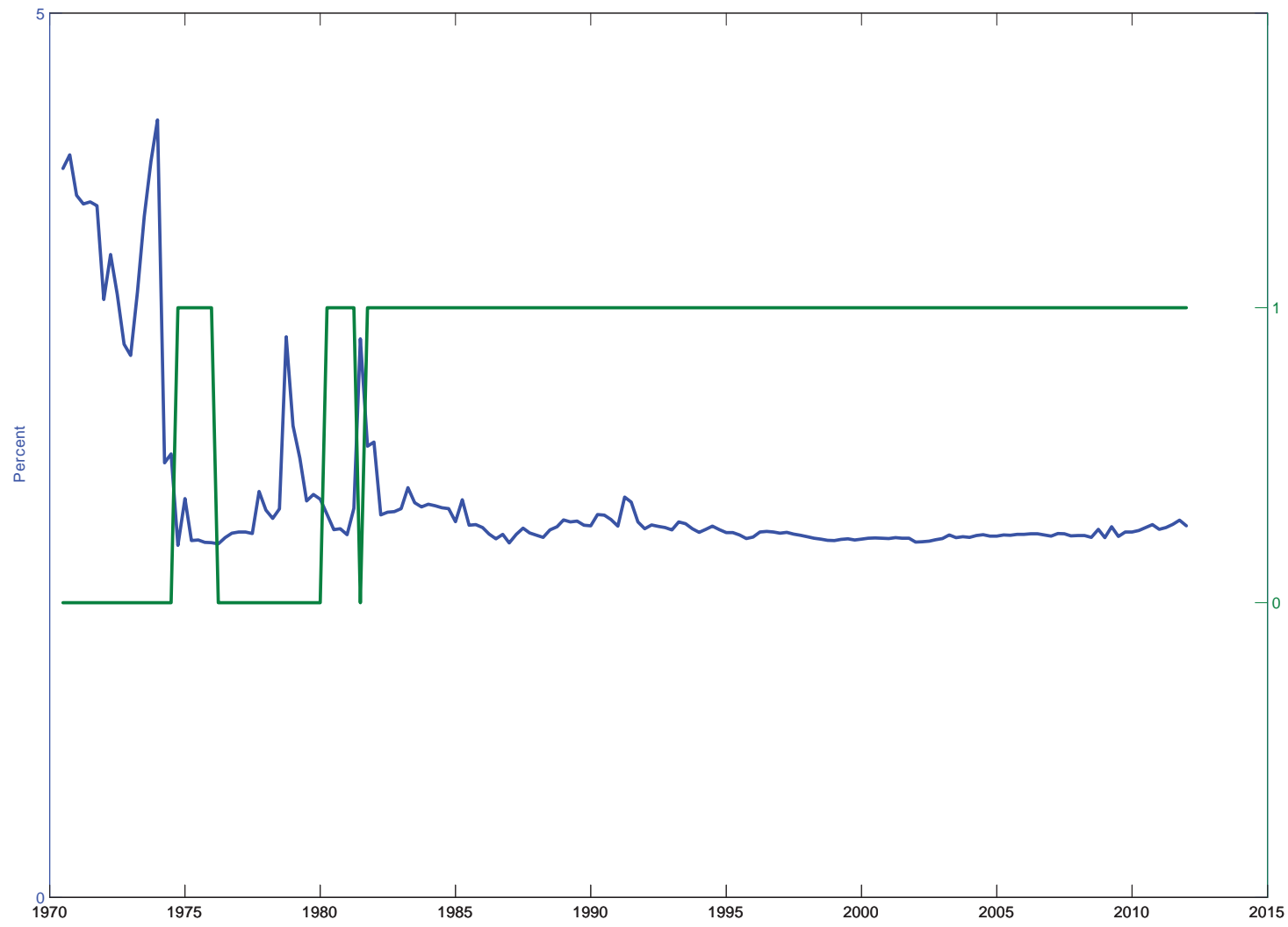

Figure 9: Perceived Long-Run Level of Inflation 


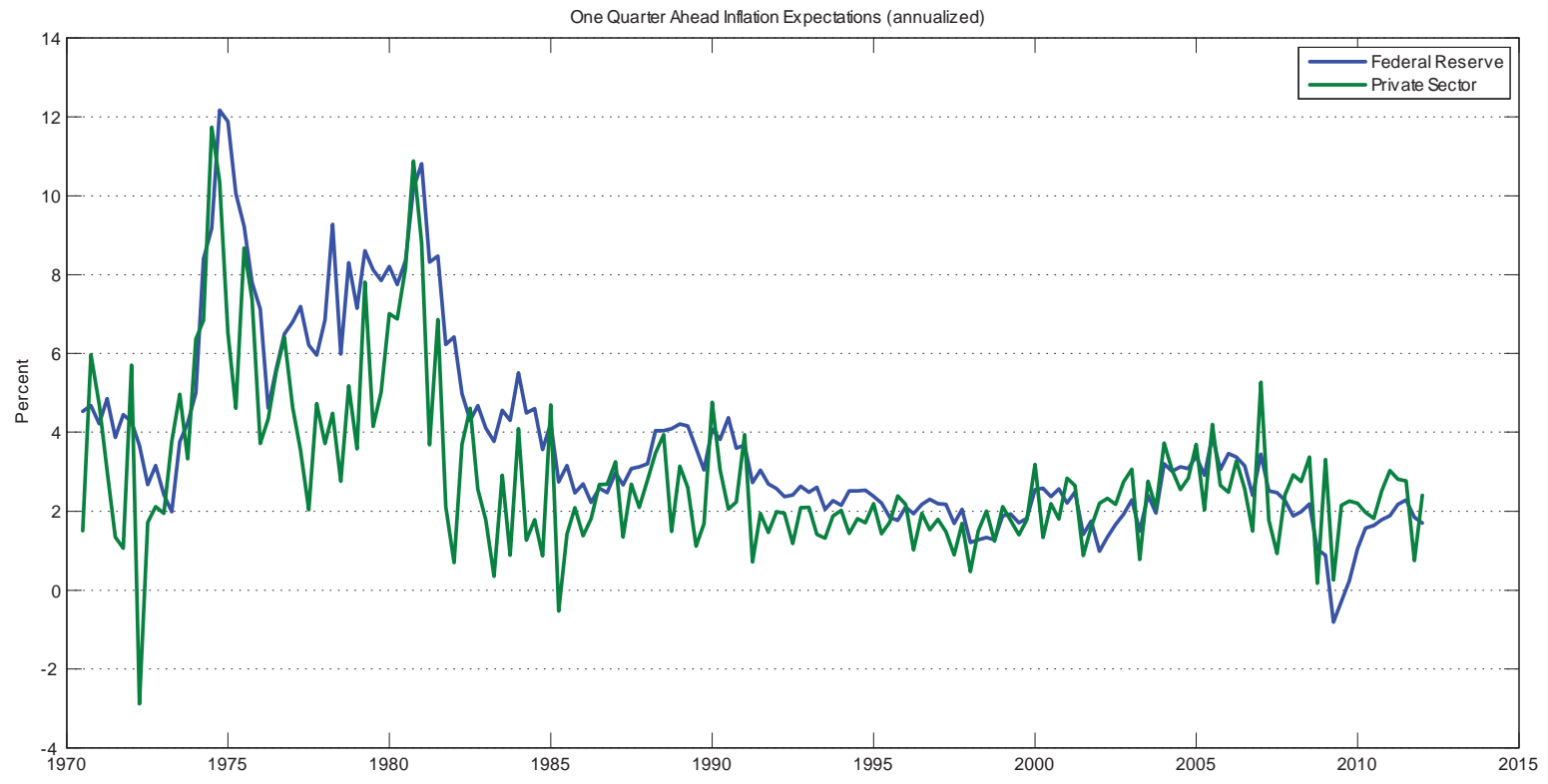

Figure 10: Implied Inflation Expectations: Benchmark 


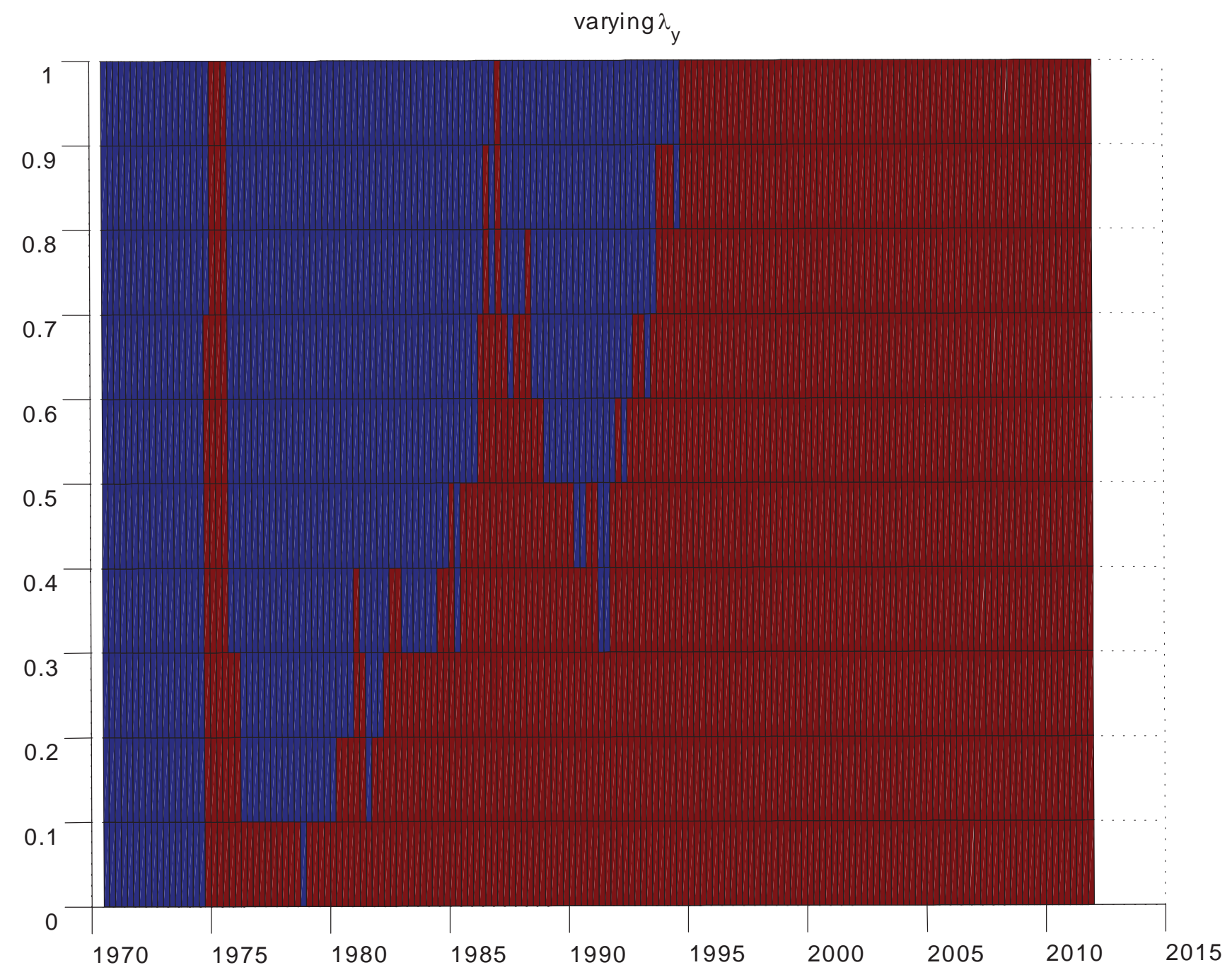

Figure 11: Sensitivity of Determinacy Indicator to Parameters: Output 
varying $\lambda_{i}$

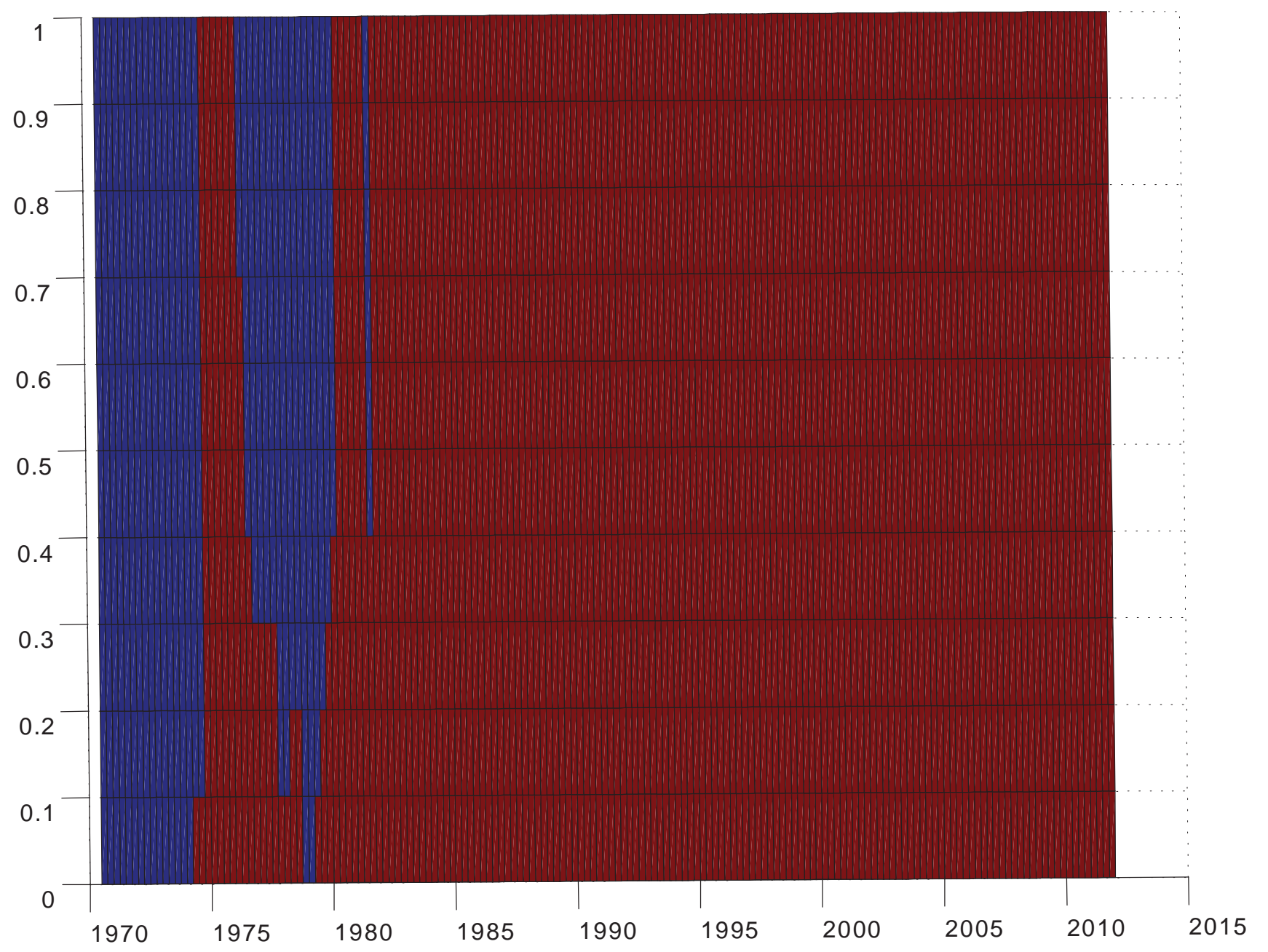

Figure 12: Sensitivity of Determinacy Indicator to Parameters: Interest-Rate Smoothing 


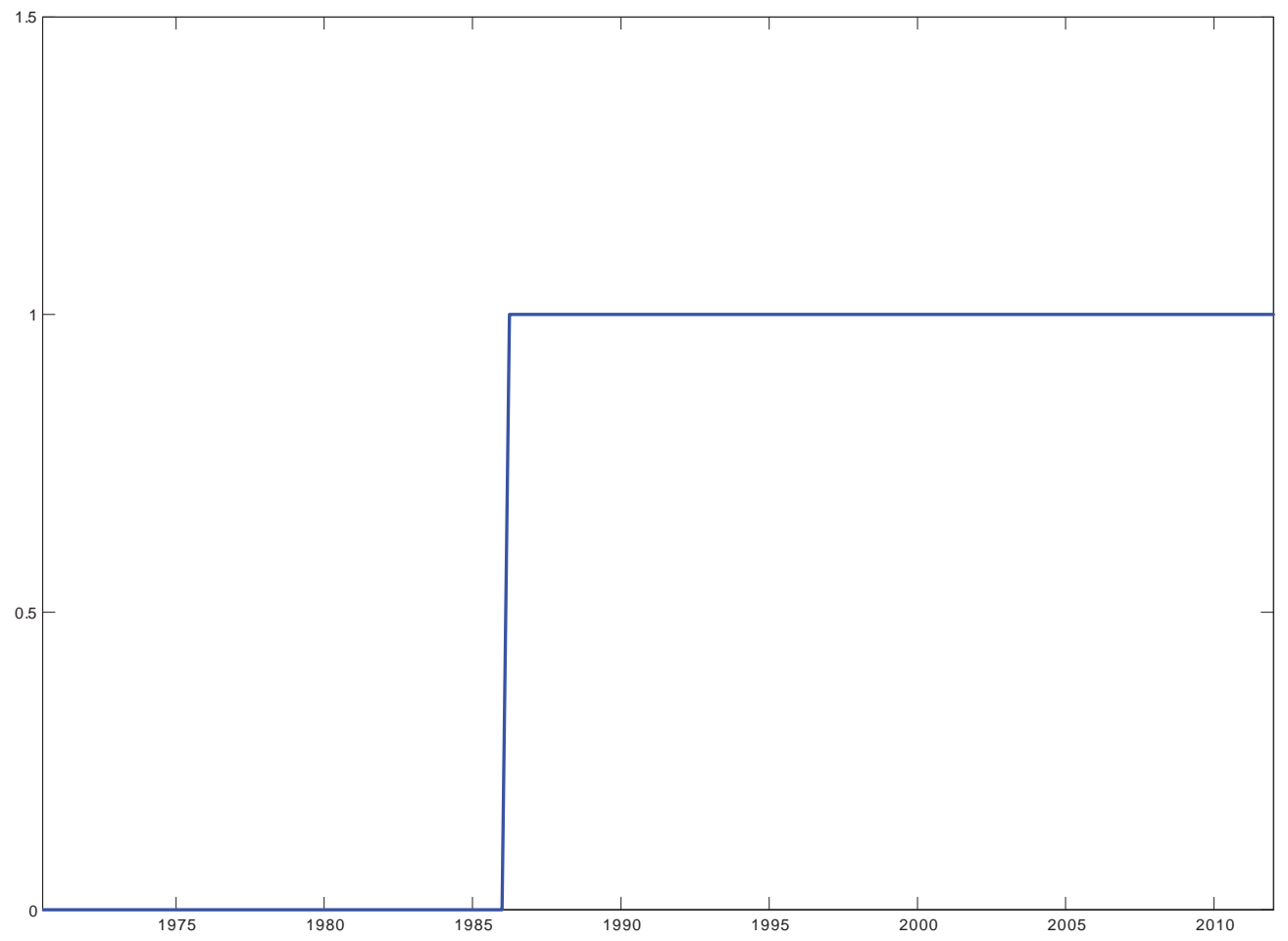

Figure 13: Determinacy Indicator under Alternative Initial Beliefs 


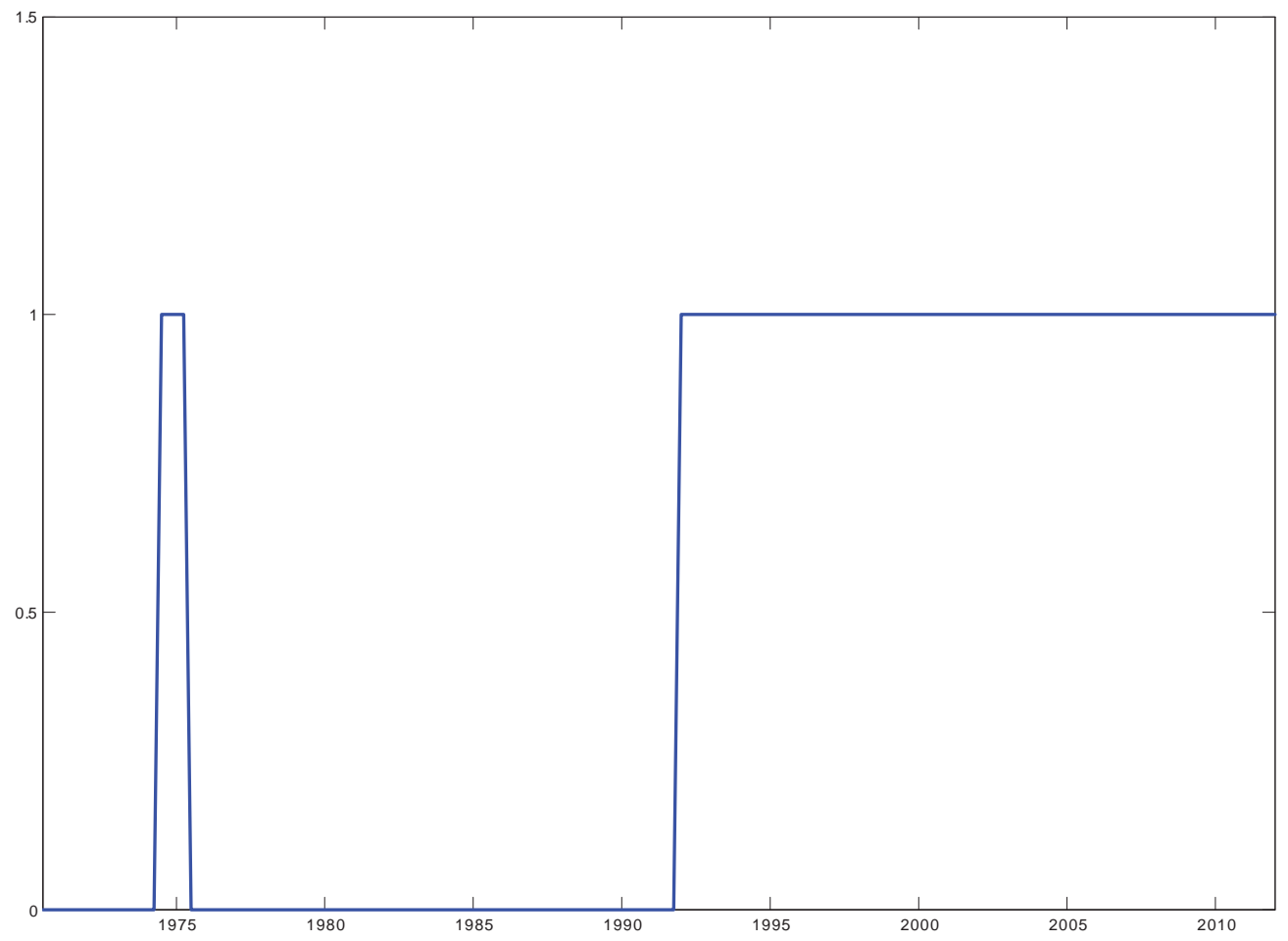

Figure 14: Determinacy Indicator without Measurement Error 